This item was submitted to Loughborough's Research Repository by the author.

Items in Figshare are protected by copyright, with all rights reserved, unless otherwise indicated.

\title{
Statesmen or cheerleaders? Using topic modeling to examine gendered messages in narrative developmental feedback for leaders
}

\section{PLEASE CITE THE PUBLISHED VERSION}

https://doi.org/10.1016/j.leaqua.2019.101308

\section{PUBLISHER}

Elsevier

VERSION

AM (Accepted Manuscript)

\section{PUBLISHER STATEMENT}

This paper was accepted for publication in the journal The Leadership Quarterly and the definitive published version is available at https://doi.org/10.1016/j.leaqua.2019.101308.

LICENCE

CC BY-NC-ND 4.0

\section{REPOSITORY RECORD}

Doldor, Elena, Madeleine Wyatt, and Joanne Silvester. 2019. "Statesmen or Cheerleaders? Using Topic Modeling to Examine Gendered Messages in Narrative Developmental Feedback for Leaders". figshare. https://hdl.handle.net/2134/9864131.v1. 
Statesmen or cheerleaders? Using topic modeling to examine gendered messages in narrative developmental feedback for leaders

Accepted for publication in The Leadership Quarterly

\author{
Elena Doldor \\ Queen Mary University of London
}

Madeleine Wyatt

University of Kent

Jo Silvester

Loughborough University 


\begin{abstract}
This inductive study extends scholarship on gender, feedback and leadership by drawing on a large naturalistic data set of 1057 narrative developmental feedback comments to 146 political leaders in the UK. We used automated topic modeling, a novel methodology, to identify 12 underlying topics within developmental feedback, and complemented this with an in-depth qualitative analyses of feedback content for male and female political leaders across the topics. This resulted in four aggregate theoretical dimensions: 1) strategic focus 2) political influence 3) confidence and 4) agency and communion. Our findings chart novel dimensions of gender bias that go beyond the widely theorized tension posed by agency [male] and communion [female]. These new dimensions are pertinent to developmental, rather than performance feedback processes, and provide male and female leaders with different developmental roadmaps. We outline the value of our novel methodology to leadership scholarship and discuss implications for future research and practice.
\end{abstract}

Key words: gender, leadership, women leaders, development, feedback, bias 


\section{Statesmen or cheerleaders? Using topic modeling to examine gendered messages in narrative developmental feedback for leaders}

\section{Introduction}

Gender inequalities persist both in leadership representation and in pathways to leadership roles. In business, women comprise a mere $5 \%$ of CEOs and $10.6 \%$ of board directors among US Fortune 500 corporations (Catalyst, 2018), and 7\% of CEOs and 29\% of boards members in UK FTSE 100 corporations (Vinnicombe, Doldor \& Sealy, 2018). Likewise, in politics, just $24 \%$ of national parliamentarian roles and $18 \%$ of ministerial positions across the world are held by women (UNWomen, 2018). Although many factors contribute to these inequalities, from persistent gender stereotyping and perceived role incongruity between leadership and 'female' attributes (Eagly \& Heilman, 2016) to organizational barriers stemming from non-inclusive cultures and processes (Eagly \& Carli, 2007), surprisingly little attention has been paid to how developmental feedback may contribute to women's under-representation in senior leadership roles. Unlike performance feedback, which is typically retrospective and comparative, developmental feedback is forward looking and individualized (Zhou, 2003); often in the form of a narrative it sends messages about how individuals need to act and, potentially, change in order to succeed and progress as leaders.

The current research extends scholarship on gender, feedback and leadership by examining whether narrative feedback pertaining to leadership development is gender biased in sending differential messages to male and female leaders. We do this through an innovative combination of automated topic modeling and traditional inductive analysis of narrative feedback. We utilize a large naturalistic data set comprising written comments about development needs $(N=1057)$ that were provided anonymously to male $(n=98)$ and female $(n=48)$ elected leaders in the United Kingdom (UK) as part of a national leadership 
development program for local government. Leaders requested feedback from colleagues and employed officials with whom they worked closely, and trusted to provide accurate and helpful developmental feedback about their day-to-day performance as a leader. To analyze these feedback comments, we combined topic modeling, a novel inductive softwareautomated text mining technique, with more traditional qualitative coding in a four-step procedure to identify differential salient messages about how men and women needed to develop in their leadership roles.

Our findings extend scholarship in two ways. First, we reveal how gender bias operates in the specific context of leadership development, through messages embedded in feedback for male and female leaders that reflect implicit stereotypes and recommend alternative developmental paths for leadership progression. We demonstrate that leadership development feedback is biased in ways that go beyond the tension posed by agency [male] and communion [female], as currently theorized in psychological literature; and that developmental feedback is less likely to direct women towards nurturing the visionary and political skills required for senior leadership roles. We integrate literatures on gender bias (Bear, Cushenberry, London \& Sherman, 2017), developmental feedback (Zhou, 2003) and leadership development (Lord \& Hall, 2005) to conceptualize when and how narrative developmental feedback can support women's leadership progression. Second, we establish the utility of topic modeling for analyzing naturally occurring narrative data routinely captured and stored by organizations, but neglected by leadership scholars as too difficult or resource-intensive to analyze (Schmiedel, Muller \& vom Brocke, 2018). Importantly, we show how topic modeling can complement traditional qualitative methods such as thematic analysis, and thus expand the methodological toolbox leadership researchers can use in producing much needed exploratory work in the field (Antonakis, 2017). In particular, we 
demonstrate the added value of this method in exploring traditionally 'hard-to-reach' HR/OB topics for leadership scholars (Hannigan et al., 2019).

\section{The role of feedback in leadership development}

Rigorous evaluative feedback is critical both to adult learning in general (Kanfer \& Ackerman, 1989; DeRue \& Wellman, 2009), and to leadership development more specifically (Avolio, 2005; McCauley \& Van Velsor, 2004; Morrison \& Brantner, 1992; Steffens et al., 2018). Feedback leads to increased self-awareness and a more accurate perception of one's performance and ability compared to others (Bollich, Johannet \& Vazire, 2011; Kluger \& DeNisi, 1996; Maki, 1998), and in the case of leaders, the availability of feedback enhances on-the-job learning (Halpern, 2004), and helps individuals make sense of, and learn from, developmental challenges (DeRue \& Wellman, 2009).

Although evaluative feedback is used widely in organizational settings (Bracken, Rose \& Church, 2016; Kluger \& DeNisi, 1996), most research has focused on performance feedback that uses quantitative ratings to assess and compare an individual's past performance against the performance of others or a norm (Speer, 2018). Much less research has investigated developmental feedback, despite its prevalence and popularity in organizations and particularly in leadership development programs (Brutus, 2010). Referred to as "valuable information that enables the employees to learn, develop, and make improvements on the job" (Zhou, 2003, p. 415), developmental feedback, like performance feedback, has an evaluative component, but it is more often personalized, forward-focused and usually provided in narrative form (Brutus, 2010). It is aimed primarily at providing individuals with information about how others perceive them, rather than benchmarking per se (Ashford, 1986).

Developmental feedback is particularly important for leaders, whose roles typically require them to navigate complex environments and conflicted relationships (DeRue \& 
Wellman, 2009; Silvester \& Wyatt, 2018), and who can therefore face greater challenge in accurately assessing the link between their behavior and outcomes (DeRue, Nahrang, Hollenbeck \& Workman, 2012). Leaders are also more likely to have difficulty obtaining candid feedback from followers fearful of reprisal (DeRue et al., 2012), therefore leadership development programs routinely provide opportunities for leaders to request anonymized development feedback regarding performance from multiple trusted sources (DeRue \& Wellman, 2009). By proactively seeking feedback from others, leaders not only improve the accuracy of self-assessments (Ashford \& Cummings, 1983), they signal their openness and commitment to personal development by acting as a role model for others (Ashford \& Tsui, 1991).

The distinctive narrative form of developmental feedback is also significant. Qualitative feedback is more likely to trigger behavior change than quantitative performance ratings (Kabins, 2016), especially when comments include prescriptive suggestions for development (Brutus, 2010). A survey of executives who received feedback consisting of both quantitative ratings and anonymous narrative comments found that these executives attended to narrative comments more than they did to numerical ratings (Ferstl and Bruskiewicz, 2000). Feedback that is specific, constructive, challenging and developmentoriented is assumed to be most helpful to leadership development (Day, 2000; Bear et al., 2017). Importantly, however, narrative feedback is also more likely to capture and communicate relational roles, cultural norms, and both in-role and extra-role expectations $(\mathrm{Li}$, Harris, Boswell \& Xie, 2011). Developmental feedback can therefore act as an important vehicle for social cues relevant to leadership identity construction (Day \& Dragoni, 2015; Ely, Ibarra \& Kolb, 2011; Lord \& Hall, 2005), through which a leader comes to see herself, and be seen by others, as a leader (DeRue \& Ashford, 2010). 
Yet despite the importance of feedback for employee development, and a wealth of advice for managers about how to provide supportive and actionable feedback (e.g. Brown, Kulik \& Lim, 2016), there is a shortage of empirical research into the content of qualitative developmental feedback more broadly (i.e. what is said and how it is said: Kabins, 2016) and whether this differs for men and women in, or aspiring to, leadership roles. Instead, most research has focused on quantitative ratings of performance and issues such as rater agreement in feedback to leaders (Day, Fleenor, Atwater, Sturm \& McKee, 2014; Markham, Markjam, \& Smith, 2015). Yet, although quantitative performance ratings have dominated research in this area (Adler et al., 2016), they likely constitute a small part of the feedback received by individuals in organizations. Importantly, a lack of research into developmental feedback is very likely due to difficulties in accessing naturalistic qualitative feedback data in organizational settings, and the complexity and time required to analyze what can be very large numbers of free-form qualitative comments by hand in order to draw meaningful conclusions. Consequently, there is a need to identify techniques to analyze qualitative feedback and thus examine its role in shaping leaders' development.

\section{Gender bias in feedback processes}

Gender complicates the developmental role of feedback for leaders. As an inherently social process, leadership development takes place in an environment suffused with ideologies about what it means to be a leader and a woman (Ely et al., 2011). Despite claims that developmental feedback challenges self-perceptions, helps individuals locate areas for development, and contributes to leadership identity construction (Ely et al., 2011), remarkably little is understood about the mechanisms by which this type of feedback may result in change (Kabins, 2016), or how these may impact differentially for male and female leaders. Developmental feedback that is specific, constructive and challenging may still vary in how 
feasible it is to action, and the narrative format of developmental feedback provides opportunity for subtle messaging about desirable change for male and female leaders. If the path to leadership is a labyrinth for women, as aptly described by Eagly \& Carli (2007), then feedback is likely to be one obstacle in this labyrinth, or a 'golden thread' that guides women to the center. Our particular interest is whether and how narrative developmental feedback might provide different advice about men and women's leadership development needs.

In addressing this research interest, we draw both on Bear et al.'s (2017) theoretical model explaining how performance feedback puts women at a disadvantage and perpetuates the gender gap in leadership; and on broader psychological research on gender bias in leadership and performance appraisal. It is important to note that, akin to the literature underpinning it, Bear et al.'s (2017) model focuses on performance feedback rather than developmental feedback. In discussing it, we therefore point out research gaps that stem from an exclusive focus on performance, rather than developmental feedback.

A key tenet of Bear et al.'s (2017) model is that performance feedback contributes to women's underrepresentation in senior leadership roles through two power retention mechanisms: feedback delivery and recipient's reactions to feedback. Our interest lies in the former. Biased feedback delivery stems from differential standards for men and women, penalties for counter-normative behavior and patronizing feedback (Bear et al., 2017). Underpinning these processes is the role incongruity (Eagly, 1987) women leaders navigate. Culturally entrenched gender roles typically ascribe communal characteristics to women (e.g. affectionate, empathetic, helpful, kind), and agentic characteristics to men (e.g. aggressive, ambitious, confident, forceful, independent). Yet, leadership remains more associated with agentic, rather than communal behaviors, leading to an enduring and global 'think managerthink male’ phenomenon (Schein, 2001; Schein, Mueller, Lituchy \& Liu, 1996). The perceived incompatibility between female gender roles and implicit masculine leader 
prototypes triggers prejudice against female leaders, resulting in biased perceptions of their suitability for, and performance in, leadership roles (Eagly \& Karau, 2002; Eagly \& Heilman, 2016). Atwater et al. (2004) provide more nuanced insight into the gender typing of distinct managerial sub-roles, noting that certain sub-roles are seen as more feminine (mentoring, rewarding, communicating, planning, and supporting), while others are seen as more masculine (disciplining, delegating, problem-solving, allocating resources, and strategic decision-making).

Due to role incongruity, while both task and relationship-oriented behaviors are important for leaders, evaluators hold men and women to different standards in both areas. Women are held to higher performance standards (Lyness \& Heilman, 2006). Observers tend to overlook women's expertise in teams (Thomas-Hunt \& Phillips, 2004), encode more easily agentic behaviors displayed by male leaders (Scott \& Brown, 2006), and record fewer incompetent behaviors in formal evaluation tools for (White) males (Biernat, Fuegen \& Kobrynowicz, 2010). Penalties for counter-normative behavior also manifest through greater scrutiny of women's interpersonal conduct in the workplace. Experimental studies found that women are penalized when withholding helpful behavior, or perceived as less likable when behaving competently at work (Heilman \& Okimoto, 2007), and receive backlash when behaving in an agentic manner because they violate gender hierarchies (Rudman et al., 2012). In male-dominated fields such as the military, women might receive less backlash for demonstrating agency, but are likely to be described with more negative attributes associated with being communal (e.g. indecisive, excitable: Smith, Rosenstein, Nikolov \& Chaney, 2018). However, by relying exclusively on numerical ratings, these studies do not capture "the what, where, when, and why of an evaluation", in the same way narrative comments can (Brutus, 2010, p. 146). 
The few studies that do draw on more naturalistic (numerical and narrative) feedback data, collected in organizational settings, reveal not only the differential standards of interpersonal and task-related behavior applied when assessing male and female leaders, but also the contradictory nature of feedback provided. Survey studies in the energy industry also found that female managers reported receiving feedback that is critical about interpersonal non-task related behaviors, but patronizing about their performance - too lenient, not sufficiently challenging and ultimately less useful to leadership development and career progression (King et al., 2012). However, this study did not account for differences in performance. In a study of Wall Street attorneys, Biernat, Tocci and Williams (2012) found that women were more likely to receive superlatives in the narrative feedback comments of their performance reviews, yet were less likely to be rated as 'partner material' in numerical ratings. Additionally, narrative ratings of technical competence mattered more for men's promotion, while narrative ratings of interpersonal warmth mattered more for women's promotion. In other words, women were harmed by not meeting gendered expectations of interpersonal warmth, but benefited less than men from meeting masculine standards of high technical competence. Wilson (2010) found a similar pattern of inconsistency in feedback provided to ethnic minority employees in banking, where supervisors systematically gave lower numerical ratings to ethnic minority staff relative to white staff, that they did not explain in their written summaries. In sum, extant scholarship on indicates that gender bias in performance feedback can obstruct women's leadership development through inaccurate taskrelated feedback, over-emphasis on interpersonal conduct, as well as patronizing or conflicting messages (Bear et al., 2017; Biernat et al., 2012).

However, our interest is not only in how gender bias shapes performance appraisal for women leaders, but how it shapes developmental forward-looking feedback, and thus the messages about how women are expected to act or change in order to progress. Compared to 
narrow performance feedback, developmental feedback is potentially more germane to women's progression up the leadership ladder, as it is future-focused (Zhou, 2003) and provides a roadmap for growth that signals not only what it takes to perform in the current role, but also what it takes to progress to the next level. Yet, there is evidence to suggest that a forward-looking focus is also subject to gender bias. Even when women's leadership competencies are recognized as equal or superior to male colleagues, their long-term leadership potential can be under-rated (Cochran 1999, in Ely et al., 2011; Ibarra \& Obodaru, 2009). Ely et al. (2011) theorize that feedback processes can obstruct leadership development by presenting women with contradictory messages stemming from the double binds of gender vs leadership roles (e.g. be softer but also more assertive), thereby making it more difficult for women to develop leader identities. However, while we have robust evidence on how gender shapes what is encoded and communicated in performance-related feedback processes, with few exceptions (Ibarra \& Obodaru, 2009 examined 360 feedback numeral ratings) empirical studies have not yet examined the nature of gender bias in developmental feedback processes. To the best of our knowledge, ours is the first study to examine gender bias in narrative developmental feedback data.

In the current paper, we aim to tackle these theoretical and methodological research gaps through an exploratory qualitative study that draws on narrative feedback provided to male and female political leaders. Our broad research question is: What messages are imparted to male and female leaders through developmental feedback? We utilize topic modeling, an automated form of content analysis that is novel to OB/HRM and leadership research, yet gaining traction in political science (Mildenberger \& Tingley, 2017) and management studies (Hannigan et al., 2019). Topic modeling is a method capable of inductively analyzing large numbers of qualitative feedback comments to generate a framework of emergent themes (topics) that can be used to guide further in-depth analysis 
using more traditional thematic analysis. Our second aim is therefore to respond to calls for more qualitative research in leadership (Parry, Mumford, Bower \& Watts, 2014) by building on advances in computerized analysis (i.e. topic modeling) to analyze naturally occurring qualitative feedback data routinely captured by organizations, but neglected by leadership scholars as too difficult or resource-intensive to analyze (Schmiedel et al., 2018, Speer, 2018).

\section{Method}

\section{Research context}

The context of this study is data collected in a developmental feedback process, which formed part of a formal leadership development program, established to provide local politicians across the UK with access to political learning. Although there are differences between political leaders and those in traditional business contexts in terms of the power that politicians hold to shape their roles and define performance, the characteristics and behaviors required in both forms of leadership are comparable (Silvester, 2008; Silvester \& Wyatt, 2018). Political and business leaders alike are expected to set strategic agendas, inspire others, sell their vision, align competing agendas, manage resources, build alliances and negotiate effectively (Buchanan, 2016; Silvester, Wyatt \& Randall, 2014). Women in politics also experience similar barriers to leadership as women working in corporate contexts. For example, female politicians are evaluated against agentic leadership ideals, such as competitiveness and power seeking (Bjarnegård \& Murray, 2018; Childs \& Hughes, 2018; Schneider, Holman, Diekman \& McAndrew, 2016). Examining feedback in a political setting therefore provides an opportunity to identify theoretical and practical implications for women's leadership identity development across diverse organizational contexts.

However, an important difference between business and political leadership roles is that politicians generally receive very little formal in-role development (Silvester \& Wyatt, 
2015), as they are expected to rely on the support of public or civil servants rather than acquire technical expertise themselves. Having to balance their political roles with paid employment and family/life activities, also means that local politicians often lack the time to engage in development activities. As a result, most developmental feedback offered to politicians is 'off-the-record' and provided on an ad hoc basis by colleagues, informal mentors or sponsors, and hard to capture (Silvester \& Menges, 2011). Thus, the present study offers a rare insight into feedback provided to politicians by individuals able to observe their day-to-day behavior in order to help inform their development as leaders.

\section{Participants and Procedure}

Participants were local politicians from the UK, also known as councillors, who are elected to the local authority (i.e. council) by the public (i.e. voters) to represent the local community on issues such as education, transport, leisure facilities, waste management and housing. There are approximately 21,000 councillors in the UK serving 418 councils. In the present research, participants $(N=146,48$ women) were local politicians from different councils in different regions who had been identified as talented councillors by their local authority. Leaders were selected to take part in a leadership development program. Participants had an average level of experience of $4.49(S D=4.03)$ years as politicians (men: $M=4.77, S D=4.46$, women: $M=3.82, S D=2.61)$.

Each participant nominated colleagues with whom they worked, understood their role, and were able to observe them over a period of time to provide anonymous developmental feedback via an online survey. The respondent sample included other politicians from the same party, and local authority officers (i.e. non-political public servants responsible for the implementation of council policies and procedures). To ensure confidentiality, it was not possible to collect information about respondents' gender. Respondents completed an online 
feedback questionnaire that asked them, using an open-ended textbox, to identify areas where their colleague would benefit from further development, and to be as specific as possible with their comments. Respondents were advised that all comments would be provided to the politicians in the form of a written feedback report. The total number of respondents was 1478 and of these 1057 provided developmental feedback comments. The average number of respondents per politician was $M=8.97(S D=5.26)$; there was no significant difference between the number of feedback comments provided for men $(M=9.42, S D=5.39)$ and women $(M=8.06, S D=4.92, t(144)=1.47, p=.14)$. Comments ranged from 1 to 437 words in length $(M=25.07, S D=25.34, M d n=19)$.

\section{Preliminary analyses}

As part of the survey, respondents were also asked to quantitatively rate the political leader's performance using the 21-item observer version of the Political Performance Questionnaire (PPQ: Silvester et al., 2014). Using a 1 (strongly disagree) to 7 (strongly agree) Likert scale, this questionnaire measures how well politicians perform their day to day activities across five dimensions: (1) resilience $(\alpha=.66),(2)$ integrity $(\alpha=.63),(3)$ analytical skills $(\alpha=.74),(4)$ representing people $(\alpha=.70)$, and (5) relating to others $(\alpha=.76)$. We used regression analyses to establish the relationship between gender and these five dimensions, controlling for participants' percentage of votes and their party's performance during their most recent election. We then combined the results into a single seemingly unrelated regression model and these analyses showed that gender was not a significant predictor of quantitative performance ratings of resilience $(\beta=-.00, \mathrm{p}>.05, \mathrm{CI}[-.17, .17])$, analytical skills $(\beta=-.12, p>.05, \mathrm{CI}[-.28, .05])$, representing people $(\beta=-.16, \mathrm{p}>.05, \mathrm{CI}[-.00, .33])$ or relating to others $(\beta=.11, p>.05, \mathrm{CI}[-.04, .27])$, however women were rated higher for integrity $(\beta=.23$, $\mathrm{p}<.05, \mathrm{CI}[.05, .40])$. These results were corroborated with a Wald test that showed there was a significant difference in the coefficients between men and women $\left(\chi^{2}(5)=18.52, \mathrm{p}<.01\right)$. We 
also conducted an analysis of the participants' percentage of votes in their local election, when controlling for the success of their party in the wider electoral division (party performance), enabling us to establish the politicians' influence on the vote separately from that of their political parties', which showed that gender was not significantly associated with electoral performance $(\beta=-.19, \mathrm{p}>.05, \mathrm{CI}[-.52, .13])$. Therefore, although performance ratings are not closely related to our theoretical focus in the current study, it is nevertheless noteworthy that the qualitative findings discussed below did not occur in the context of lower performance ratings or electoral performance for women.

\section{Data Analysis and Findings}

Our analytical approach was inductive and entailed four main steps. Figure 1 provides an overview of the data analysis process. Inductive approaches are methodologically fit for underexamined and less theoretically mature research areas (Edmondson and McManus, 2007; Neuman, 2006) such as qualitative leadership development feedback (Speer, 2018). In contrast to top-down hypothesis testing characteristic to a deductive approach, an inductive approach allows for bottom-up identification of key themes emerging from qualitative data. In this study an inductive approach allowed for the exploration of the knowledge held within naturally-occurring qualitative data. The shift from Step 1 to Step 4 in our data analysis process (Figure 1) reflects a gradual movement from organizing to interpreting data (Ritchie and Lewis, 2003), typical to inductive qualitative analyses.

\section{INSERT FIGURE 1 HERE}

Step 1: Software generated topic model. Given the number of feedback comments in our data set (i.e. $N=1057$ ), we used topic modeling to provide an organizing framework for our 
qualitative analyses. This computerized method of sorting text describes qualitative documents in terms of a set of underlying themes or latent topics. Unlike software traditionally used to analyze qualitative data, such as NVivo, topic modeling sorts text using an unsupervised algorithm, which means it does not require the researcher to identify hypotheses or a priori codes because the process is automatic, inductive and data-driven. Topic modeling is therefore particularly useful for identifying themes in a large volume of qualitative data, which may be unmanageable to code by hand. Despite its potential for gaining insight into organizational phenomena, especially the form of qualitative feedback data routinely stored by organizations that has hitherto been difficult to analyze manually, topic modeling has yet to be widely used by organizational scholars (Banks, Woznyj, Wesslen \& Ross, 2018; Schmiedel et al., 2018). However, researchers in disciplines such as information and political sciences have found the method valuable, for example for analyzing the content of text in open-ended opinion surveys (Mildenberger \& Tingley, 2017) and tweets during political campaigns (Roberts et al., 2014; Yoon, Kim, Kim \& Song, 2016). It is particularly suitable for the aims of the current study because the inductive nature of topic modeling enables the examination of latent frames in qualitative data, providing an opportunity to identify how feedback messages are imparted to male and female leaders differently in order to generate new theory (Hannigan et al., 2019).

The most common algorithm for topic modeling is Latent Dirichlet Allocation (LDA: Blei, Ng \& Jordan, 2003), a basic premise of which is that topics are based on probability distributions over all words across all documents being analyzed. For example, if analyzing the content of British newspapers in 2019 using an LDA model to find two latent topics, the LDA algorithm might automatically identify Topic A to include words such as 'Europe', 'Brexiteers', 'Remainers' and 'Parliament', in comparison to Topic B which may more likely contain words such as 'climate', 'recycling', 'carbon' and 'emissions'. Those words with high 
probability are often then used by researchers to label the topic, so that Topic A could be labelled 'Brexit' and Topic B might be labelled 'Climate change'. Another assumption of LDA is that documents consist of multiple topics with different probabilities; for example, the content of Newspaper 1 might be 70\% Brexit and 30\% Climate change.

Because the topics are latent and not readily observed, LDA works backwards using an unsupervised machine learning algorithm to explain the observed documents using the topics that could have generated them (see Blei et al., 2003 and Blei, 2012 for a detailed description of the LDA algorithm). In the first stage the researcher specifies how many topics the model should extract from the data (but not their content). Second, LDA randomly assigns every word to a topic according to a Dirichlet distribution ${ }^{1}$. Finally, to improve the model, the algorithm updates these topic assignments based on the likelihood that the word would appear in the topic across different documents, and how common the topic is in the rest of the document. As the model runs through each word and reassigns topics, the model becomes more consistent. Because this process focuses on how words co-occur within specific contexts, it allows the same word to appear in different topics and for the function and meaning of words to change. For example, the word 'present' might appear in a topic about 'being present at meetings', but also about in a topic about 'how individuals present themselves'. As such, topic modeling provides a more holistic view of qualitative data than methods that simply examine the frequency of single words within a document (Schmiedel et al., 2018) $)^{2}$.

\footnotetext{
${ }^{1}$ The Dirichlet distribution is a probability distribution commonly used as a prior distribution in Bayesian statistics

${ }^{2}$ In fact, our first attempt to analyze the feedback comments involved examining the word frequency with the Linguistic Inquiry and Word Count program (LIWC: Tauscik \& Pennebaker, 2010). This 'top-down' analytical method involved designing a bespoke dictionary of words associated with developmental advice (e.g. "communication", "enthusiastic", "motivated") and using the LIWC to count occurrences of these words. However, we found that the data contained too many ambiguities, subtle meanings, hedging and contradictions making word counts less useful for interpretation. Counting words also removed the possibility of examining the data inductively. Topic modeling was therefore more appropriate because it enabled a 'bottom up' inductive analysis to explain co-occurrences of words within the feedback comments, and allowed for synonymy and polysemy (i.e. the same word can hold the same or different meanings across the data).
} 
In this study, we used an extended version of LDA: Structural Topic Modeling in R (STM: Roberts, Steward \& Tingley, 2014). This method allows the use of covariates to structure the prior distributions in a topic model and uses a regression framework to understand how covariates influence how frequently topics are discussed (i.e. prevalence) and also how the word use within topics varies (i.e. content). When specifying the model, we assigned gender as a content covariate because this allowed us to examine how the language in each topic differed for men and women.

To prepare the data for topic modeling we pre-processed the feedback comments. This involved spellchecking to ensure consistency. Following Piepenbrink and Gaur (2017) we used the textProcessor function in the R package tm to convert all words into lower case, remove punctuation and words that are highly used but not relevant to the analysis (e.g. 'and' or 'the'), as well as political leaders' names. In this process we also ensured our analyses was conducted only on meaningful text by removing comments that had 'none', 'not applicable' 'don't know' or 'N/A' type content, which reduced the number of comments being analyzed to $\mathrm{N}=965$. We also added several bigrams (i.e. two words that are often adjacent) so that the software captured discussion of skills such as 'time management' and 'public speaking'. We chose not to stem the words for analysis, a process that removes the ending of words (e.g. 'decision' and 'decisive' would be reduced to the stem 'decis') because this can make topics more difficult to interpret, and may also overlook important nuances within the developmental feedback (Schofield \& Mimno, 2016).

Once we had pre-processed the data, the next stage was to identify the number of topics to extract. Although this can be established through statistical measures, these measures may not always identify the most useful topics as judged by human raters (Chang, Boyd-Graber, Gerrish, Wang \& Blei, 2009). We therefore used a mixture of different indicators, involving computer guidance (see Appendix 1) and human judgement, to select the 
number of topics. First, we used the STM package to run models with between 5 and 25 topics and for each model we examined (a) semantic coherence, which is a statistical measure of how interpretable topics are based on how likely different words were to occur together (Mimno et al., 2011), (b) FREX, which is a measure of how frequent and exclusive words were to each topic, looking to avoid topics that had too many similarities (Airoldi \& Bischof, 2016), (c) the document-completion held-out likelihood, which is a measure of how well each model predicted words within the comments (Wallach, Murray, Salakhutdinov \& Mimno, 2009) and (d) dispersion of residuals in the model, where lower values indicate a better specified model (Taddy, 2012). Our analysis found that there were ideal values for each of these indicators in models with 10, 12 and 15 topics, but that a model with 12 topics offered the best balance between all four indicators. Table 1 provides the words that had the highest probability of belonging to the 10,12 and 15 topic models, as generated by the STM software.

\section{INSERT TABLE 1 HERE}

Second, we examined how interpretable the topics were from the 10, 12 and 15 topic models using a word intrusion task (Chang et al., 2009). This method involves asking human interpreters to find intruding words that are placed within existing topics; if the meaning of topics is clear then intruding words are easy to identify. Two researchers familiar with the political context were presented with a list of words representing each topic and asked to identify randomly chosen intruding words that did not belong in the top words of the topic; for example, with a list of \{decision, making, officer, getting, done $\}$ the word officer was an intruder. A higher percentage of intruding words were identified in the twelve-topic model $(M=42, S D=0)$, than the models with five $(M=10, S D=14.14)$, ten $(M=30, S D=0)$, or fifteen $(M=17, S D=14.14)$ topics, with a moderately good level of inter-rater agreement $(\kappa=.51$ : 
Fleiss, 1971). These analyses suggested that the model with 12 topics was the best quality because intruders were easier to identify, and this is a suitable number of topics given the length and number of comments in the data (Banks et al., 2018).

The top words for the 10-, 12- and 15-topic models (Table 1) show that although there are many similarities across the models, the 10-topic model lacked detail in comparison to the 12-topic model. For example, topics 4 and 9 in the 10-topic model are less specific and the content concerning officers (in topic 12 of the 12-topic model) is lost entirely. In the 15-topic model we also start to see topics that are vague and difficult to interpret. For example, the top words from topic 7 are 'getting', 'occasionally', 'making', 'rather' which lack specificity. The interpretability and specificity of top words therefore further corroborates the choice of the 12-topic model. In summary, the first stage of the analysis involved using structural topic modeling to organize the qualitative comments into a framework of 12 underlying topics.

Step 2: First-order descriptive topic summaries. Step two of the analysis involved a more inductive, researcher-led interpretation of the 12-topic model generated by the software, to provide a first order descriptive summary of the topics by identifying key messages conveyed about leadership development in general, regardless of gender. To this aim, and following Pipenbrink and Gaur (2017), we examined the 65 most representative feedback comments for each topic (top 5\%), which were comments that had the highest probabilities of including the topic, as identified by the STM software. We found the 12 topics were straightforward to interpret and the content of the top comments were consistent with each topic summary. For instance, the top words for topic 10, which we labelled 'party political work', were 'opposition' 'group', 'within' and 'team', which suggested that the topic concerned working in political teams or groups. Indeed, the top comments for this topic provided feedback on ability to work with opposition parties, being a team player and group 
(i.e. party) loyalty. Table 2 presents all 12 topics, together with the labels we assigned, descriptive summaries, top words, and illustrative feedback comments.

\section{INSERT TABLE 2 HERE}

Although our research questions were concerned with the content of topics, we wanted to first establish whether there were any differences in how often the topics appeared for men and women. We therefore used regression analyses to examine the prevalence of the topics identified in relation to gender, using the topic proportions for each comment provided by the STM package. We transformed the twelve topic proportions using logit transformations to account for their bounded nature (Baum, 2008; e.g. $\ln ($ topics 1/(1-topic 1)) to form twelve outcome variables, which we predicted with gender, the percentage of votes participants had achieved in the election and their party electoral performance as controls. Using Stata 15, we combined these in a seemingly unrelated regression with a cluster robust estimate of variance where the data was clustered based on the political leader being rated (see Table 3, means, standard deviations and correlations for all study variables are provided in Appendix 2). The results demonstrated that neither the percentage of votes achieved nor the party performance impacted how frequently topics were discussed; there were also no gender differences in topic prevalence, which was supported by a Wald test on the gender coefficients $\left(\chi^{2}(11)=13.51\right.$, $p>.05)$. These analyses demonstrate that participants' electoral performance had no impact on how often topics were discussed, and that all twelve topics were discussed as frequently for men as they were for women.

INSERT TABLE 3 HERE 
Step 3: Second-order gendered messages within topics. Once the topics were established and interpreted, we sought to identify second-order gendered messages within each of the twelve topics that might reflect potentially different feedback provided for male and female political leaders about their developmental needs. We achieved this by comparing the top 40 comments received by male and female politicians (thus a total of 80 feedback comments per topic) that had the highest probabilities of representing each topic, as identified by the STM software. Although some overlap may occur with longer comments that may fit more than one topic, this step entailed an inductive researcher-led analysis of 960 comments in total (i.e. $91 \%$ of the original data set: 1057 feedback comments). In identifying messages salient per gender, we took a 'bottom-up' approach to categorizing emerging messages. For example, whereas Step 2 of the analysis identified the overall message of Topic 4 (Public speaking) "Be more relaxed and improve clarity of speech when speaking in public" as common to both men and women, Step 3 of the analysis sought to identify what - if anything - was distinctive in the feedback received by women and men for a topic through inductive coding. In line with inductive coding approaches to qualitative data (Cassell, Cunliffe \& Grandy, 2017; Doldor, Silvester \& Atewologun, 2017) we looked for common recurrent messages in each sub-set of feedback comments for each topic, per gender. Thus, for Topic 4 recurrent feedback comments for women included nervousness and lack of confidence in public speaking, and being too abrupt in communication, that were less apparent in feedback to men. Conversely, men were advised to be more forceful and challenging, yet measured and strategic when communicating - advice that was not present in feedback to women.

In extracting gendered messages emphasis was on capturing how issues were framed, thereby tapping into the richness of qualitative data. For instance, in Topic 1 (Experience) time management was mentioned for both men and women, but discussed differently: for men, time management was referred to as a routine skill in need of development, but for 
women advice for improving time management was couched in comments about 'taking on too much', needing 'to relax', thus hinting at an overall impression that women are (seen as) overwhelmed and frazzled by the demands of their role. We believe these nuances are important. Following good practice in qualitative research (Dacin, Munir and Tracy, 2010), we ensured trustworthiness in the analysis underpinning Step 3 by discussing our independent interpretation of the messages in women's and men's feedback until there was clear agreement. Table 4 reports for each topic (1) the common general message given to both men and women, (2) gendered messages mostly salient in feedback given to women and men, and (3) illustrative feedback comments. Therefore, following Aguinis and Solarino's (2019) criteria for transparency in qualitative research, Table 4 provides the full list of our second order codes.

\section{INSERT TABLE 4 HERE}

While frequency counting is debated in qualitative analysis, using numerical data to quantify patterns identified inductively allows researchers to establish 'internal generalizability' - i.e. how robust the findings are within the set of individuals examined and can reveal patterns that are not obvious from unquantized qualitative data (Maxwell, 2010). Therefore, to further establish that within-topic messages were indeed gendered (i.e. that 'female messages' were given predominantly to women and 'male messages' were given predominantly to men), two of the authors coded independently the frequency of these messages in each sub-set of top 40 feedback comments per gender per topic. This was done by independently assigning ' 1 ' when a specific gendered message was present in a comment, and '0' when it was not: Kappa values ranged from .63 to .90 indicating substantial agreement between the two authors' coding (Fleiss, 1971). Table 5 reports frequency counts and Chi- 
square results, demonstrating that frequency differences were statistically significant for female and male messages for all twelve topics.

\section{INSERT TABLE 5 HERE}

Step 4: Aggregate theoretical dimensions. Extracting second-order gendered messages within topics during Step 3, revealed some similarities across topics. For instance, advice to men about being strategic was recurrent across topic 4 (articulate a vision), topic 7 (consider 'big picture' when making decisions), and topic 11 (think strategically about which goals to focus on). Thus, our final analytical step was to organize second-order gendered messages into more abstract overarching dimensions, a practice often described in qualitative research as 'axial coding' (Strauss and Corbin, 1990). In determining these theoretical dimensions, we first grouped and visually examined the gendered messages received by men and women across all topics; we then iteratively clustered messages into broader categories, gradually noticing that these categories represented different advice on the same broad dimension ${ }^{3}$. For instance, whereas in men's feedback we found several references to the importance of setting a vision (indicative of a strategic, visionary focus), in women's feedback we found abundant advice about the importance of being knowledgeable and getting things done (indicative of an operational, hands-on focus). This led to the first theoretical dimension 'Strategic focus'. Drawing on best practice in qualitative research (Aguinis and Solarino, 2019; Corley and Gioia, 2004; Mantere, Schildt, and Sillince, 2012), Figure 2 illustrates how the various gendered messages identified in Step 3 were grouped into high-level aggregate theoretical

\footnotetext{
${ }^{3}$ While the majority of messages identified in Step 3 were clustered, our aim was to find broader dimensions that were salient across the topics, rather than to exhaustively allocate all gendered messages. Four gendered messages (out of 26) were not included in the final theoretical dimensions (see Table 4), either because they raised marginal issues irrelevant to the broader dimensions identified, or because they were 'lone' messages lacking wider salience across the data.
} 
dimensions. The four theoretical dimensions we identified relate to: (1) Strategic focus; (2) Politics and influence; (3) Confidence; and (4) Agency and communion.

\section{INSERT FIGURE 2 HERE}

Below we expand on the content of the aggregate theoretical dimensions identified, and signal how gendered messages across various topics $(\mathrm{T})$ cluster to provide different developmental roadmaps for female and male leaders.

\section{Strategic focus: "Setting the vision vs Getting things done". The first aggregate}

theoretical dimension identified in Step 4 reflected differential feedback that, in broad terms, encouraged male leaders to foster a strategic mindset, and women to focus more on operational detail. Despite encouragement for both men and women to be clearer about a strategic vision for their role (T3, T5), men were encouraged to focus on developing a personal vision and to set out long term political strategies rather than allocating time to short-term goals (T11). Conversely, women were advised to set goals and objectives and prioritize time better in order to deliver the vision of the local authority. For example, feedback to men emphasized a need to focus on the future and develop political ambition:

He has real potential to rise to the most senior levels in politics but probably now needs to reflect on that longer-term ambition and political strategy and wider political thinking in a more intellectual/academic context to achieve that potential. (T3, M, $\left.\mathrm{P9} 2^{4}\right)$

\footnotetext{
${ }^{4}$ The codes assigned to illustrative quotes signify gender and participant number for the leader in receipt of the feedback comments, not for the feedback provider. For instance, this first quote is feedback from Topic 3 , provided to participant number 92 , who is a male leader.
} 
Forgetting the detail and looking to the longer-term and the direction. Drawing together strands of information to form a wider and comprehensive web of understanding that would allow for more strategic thought and action. (T5, M, P107) Feedback to men also stressed the importance of gaining knowledge about governmental functions and processes in order to form a successful political strategy. Distinctive messages pointed men towards understanding 'the bigger picture' and developing relationships with others to afford wider exposure to the workings of national and local government (T6). For instance, one male leader was told they needed:

More focus on national and regional agendas for local government; leading a strategic rather than operational review. (T6, M, P15)

In contrast, messages to women were focused more on acquiring knowledge in specific technical and operational areas, or relating to relatively narrow policy issues at a local level (T6). Where they received feedback about vision or political strategy, this focused more on developing the understanding and capabilities needed to implement rather than create strategy (T3, T5, T6):

Creating greater cohesion between political vision and service operations and priorities. (T3, F, P75)

Make clear the vision and key objectives for [the local authority] beyond the five council priorities which should drive the city strategies in the department. (T5, F, P56)

Needs to have better analytical abilities with complex issues for example complex redevelopment project in [town name]. Needs to have a better appreciation of the long term: 5-year vision. Sometimes expresses knowledge on a subject on which she has little. (T6, F, P9) 
Women were also advised to be mindful of the positioning of different groups (T6, T9) in order to develop support to achieve objectives. Whereas men were encouraged to take a directive stance to action their strategic vision (T7, T12):

[She] would benefit from developing an ability to listen to others and not always be so focused on her objectives. She also needs to understand that not everybody is as committed as she is. (T9, F, P21)

Needs to be more confident and assertive-become more of a community leader; should speak out more about his views. (T12, M, P132)

These findings indicate a pattern whereby men are encouraged to be strategic and to approach leadership with a 'big picture' mindset, and are directed towards a pathway that sees them as instrumental in creating a vision to guide their own and others' success. On the other hand, women are directed towards developing technical expertise relevant to relatively narrow (and therefore ultimately less influential) issues, and thus set on a pathway to help enact the vision of others.

2. Politics and Influence: Leveraging vs Coping with politics. Most notable in the second aggregate dimension is the prevalence and distribution of messages across topics for male and female leaders. Four messages were identified across three topics (T1, T3 and T10) in feedback to women leaders, and eight messages across six topics in the feedback to men (T2, T3, T7, T9, T10 and T12). In general, men were advised to be proactive political players and to enhance their political strengths, by learning to persuade others and build networks (T2, T9, T10). In contrast, women received feedback suggesting they needed better political skill to achieve their goals (T1); an implicit message describing them as naïve to the political context, and insufficiently resilient when faced with political games or conflict (T3, T10). 
Moreover, feedback messages received by male leaders were repeatedly infused with detailed advice about how to work politically. Men were encouraged to gain insight into the interests, motivations and needs of others, in order to better position themselves to recognize and balance the interests of different stakeholders (T2, T7, T9), for example:

Developing politics as a 'language'. Knowing the plethora of interdependent relationships around him to enable him to use his skills to develop politically. (T2, M, P85)

And whereas women were encouraged to focus on managing relationships horizontally and downwards (i.e. peers and team members) to gain support, men were advised to manage relationships within their groups, but also upwards and outside the political party, developing currency with a broader network in order to build their power base and gain endorsement (T10). For example,

[She] needs to work with other councillors who are on a lower level especially within her own party. She appears to reject the relationships that should be made at group level which she may need for future advancement in the group. (T10, F, P2) Managing dynamics within the political group and building broader alliances with those who hold power. Recognizing how to get the balance between working out how to get what he wants through, when it's better to live to fight another day, and having some effective fall backs. (T10, M, P63)

Men, unlike women, were cautioned against engaging in too much politicking for short term point scoring (T3), suggesting a need for more subtlety (or savvy) and restraint in order to broker alliances and work across political groups. For example, one male leader was advised:

[He] sometimes makes comments which can be perceived as glib, disrespectful or unthoughtful, generally in the context of wanting to "wind up" political opponents $A$ 
more measured approach to some situations, seeking the consensus, is sometimes more effective way to achieve outcomes (T3, M, P12)

Overall, male leaders received more specific advice about handling politics than women. However, women leaders received qualitatively different feedback; the messages they received told them to be more resilient, less sensitive to politically charged conflicts and less naïve. For instance, feedback from one colleague depicts a female leader as nice but politically ineffective, another states the need for experience and exposure, and implies an inability to deal with conflict:

In talking with [her] I often get the impression that she is out of step with some of her political colleagues. I would like to believe that she has the skills and persuasion techniques to win her arguments with them more often. [She] is a confident, friendly, approachable councillor who can seem at sea with the bloody thrusts of the political chamber. More resilience in dealing with the nastier political types is needed. (T3, F, P140)

More experience of just how downright untrustworthy a lot of opposition councillors actually are! (T10, F, P87)

Overall, feedback encouraged men to build strength and actively leverage politics as a leader, while cautioning women to manage their shortcomings; depicting men and women as proactive versus defensive political players.

3. Confidence: Displaying confidence vs Being confident. The third aggregate dimension revealed a subtle difference in feedback to leaders about confidence. Men's feedback often treated confidence as a synonym for assertiveness. They received encouragement to 'project' or display confidence, particularly in relation to conveying political messages and their style of delivery (T2, T4). As such, feedback for men was more actionable, suggesting confidence 
is an impression management skill that can be learned and developed. In contrast, women were often told that they lacked confidence and they needed to be more confident (T2, T4, T8). This difference between having and displaying confidence is important, as it suggests essentialist judgements for women (Hepburn, 2003):

Sometimes [he] lacks confidence and voice tone and head drops. (T4, M, P112)

Whilst a confident person, he will sometimes not express arguments or positions forcefully enough i.e. not stand up for himself if a stronger personality has taken over a meeting. (T2, M, P101)

[She] needs to be a bit more confident and have a bit more self-belief? (T2, F, P109) The only thing that stops [her] delivering to her true potential is that she lacks the confidence that she should have in herself and her judgement. (T4, F, P35)

Although women were also given advice about improving confidence in communicating, unlike men, they were chastised for not speaking up in the first place and being too diffident in expressing themselves (T7, T9, T10):

She doesn't seem very outgoing or pro-active, really rather quiet. (T7, F, P142).

Needs confidence building in public speaking, rarely speaks in some important meetings but will when drawn out, her views are usually sound but sometimes afraid of expressing them. (T9, F, P55)

However, women also experienced a 'double bind' in this regard, because they were also criticized for being too enthusiastic or expressive of their views. For example, one leader was given the following conflicting advice:

Lacks confidence sometimes when dealing with others. Can sometimes be overenthusiastic about her ideas. Sometimes needs to be more forceful with officers and political colleagues. (T2, F, P120) 
Overall, this aggregate dimension revealed a subtle underpinning belief in male and female leadership potential, with comments framing men as 'fixable' through actionable feedback encouraging them to exhibit more confidence in specific areas, compared to feedback to women that offered little actionable advice about how to develop confluence, and framing women as more fundamentally flawed in their lack of conviction and self-belief.

4. Agency and communion: Claiming your space vs Getting along. In the fourth aggregate dimension we identified clustered gendered messages around agency and communion in the context of becoming and being accepted as a leader. With one exception (T12 - advice to be less abrasive), the feedback provided to men encouraged them to claim their leadership space by cultivating long-term career ambition and putting themselves forward for senior roles (T5, T6, T8, T10).

I believe that [he] would benefit by taking a more prominent role at committee, either as a chairman or vice chairman. (T6, M, 144)

Due to being surrounded by more senior colleagues, [he] has not yet had much opportunity to lead teams or set tasks for other colleagues within the political group. Either this needs affording to him, or he needs to push for and actively seek such roles. (T10, M, P4)

Feedback provided men with a much clearer mandate to take on the mantle of leadership. Men were also more likely to be offered grand depictions of their future selves as leaders, and to be enthusiastically praised for leadership potential that they were advised to deliberately develop (T1, T5, T9). Feedback often suggested, implicitly or explicitly, that men merely needed time and experience to flourish as leaders (T1, T8):

Nothing a few more years' experience wouldn't put right, has Member of Parliament stamped on his forehead! (T1, M, P53) 
He needs to be given more responsibility to broaden his experience. The ability is all there; he just needs the opportunity to develop (T1, M, P18)

He is an outstanding young man. I think all he needs now is to continue to grow with his strengths. (T8, M, P31)

In contrast, there was abundant advice counselling women to be collegiate, considerate, tolerant, compliant, or even deferential in their council work, that also included a subset of messages focused on displays of emotion (particularly frustration), and on resilience building (T8, T10, T11, T12):

Learn to work collaboratively, treat people with respect. (T12, F, P44) Does not suffer fools gladly, could develop better tolerance techniques. (T12, F, P96) [She] works extremely hard and one does not want to discourage that but sometimes we all need a break to avoid getting tired and irritable. Precisely because [she] is so genuinely nice, if she is occasionally brusque with people it has more effect than from someone else, she needs to be aware of that. (T11, F, P22)

While women were occasionally told to be more assertive, to manage colleagues more effectively (T2), or to lead in a more consultative way (e.g. T7, T10), the overarching feedback underpinning this dimension was clearly centered around getting along with others (T2, T4, T7, T8, T10, T11, T12), rather than leading them. And although women were told that experience would help them achieve their potential, references to leadership potential were less salient, used a staider imagery to describe women's leadership potential in localized leadership areas:

[Name] has become an effective speaker in the chamber but could do with a little more development to be an effective cheerleader for backbenchers ${ }^{5}$ (T8, F, P111)

\footnotetext{
5 'Backbencher' is a term used to describe a councillor who is not in the executive (i.e. leadership team) of their political group in the council. It derives from the British House of Commons where 'backbenchers' sit in the rows of benches behind party leaders (e.g., Ministers), who are known as frontbenchers.
} 
She is a shrewd leader of the opposition, but I just don't know how good she would be in charge of everything, probably very good but I don't know. (T10, F, P62)

Taken together, these findings indicate that developmental feedback conveys more belief in men's leadership potential, giving men a mandate to assertively forge ahead into leadership roles, while directing women to be communal by continually attending to interpersonal dynamics.

\section{Discussion}

In this research we sought to understand the nature of gender bias in developmental leadership feedback. Drawing on an inductive analysis of a large naturalistic qualitative data set, we examined narrative feedback from 1057 raters to 146 male and female political leaders, drawing out salient messages received by men and women. Using software-based topic modeling analysis, we identified and interpreted 12 topics capturing key areas of advice for leadership development that were discussed across the entire feedback data set (Steps 1 and 2 of our analysis). While leadership performance was not our theoretical focus, it is nevertheless noteworthy that participants' electoral performance had no impact on how often these topics were discussed (all twelve topics were discussed as frequently for men as they were for women). Likewise, the qualitative differences we identified in narrative feedback did not occur in the context of lower performance ratings or electoral performance for women.

After establishing our 12-topic model, we extracted and coded gendered messages across the 12 topics (i.e. distinctive advice salient in women's and men's feedback: Step 3), which we then grouped into four higher-level aggregate theoretical dimensions (Step 4). These dimensions indicate that male and female political leaders received different feedback about 1) whether they should think strategically or more operationally, 2) how they should approach organizational politics and influence, 3) being confident or displaying confidence, and 4) expectations about agency and communion. 
Our findings extend scholarship in two ways: (1) we reveal how gender bias operates in the specific context of leadership development, through biased messages that recommend alternative developmental paths for leadership progression, and (2) we establish the utility of topic modeling for analyzing naturally occurring narrative data routinely captured by organizations, demonstrating the added value of this method in exploring traditionally 'hardto-reach’ HR/OB topics for leadership scholars (Hannigan et al., 2019).

\section{Gender bias and feedback research}

Our research extends scholarship on gender bias and feedback in several ways. Importantly, our study moves beyond a customary focus on quantitative performance feedback (Bear et al., 2017), to provide novel empirical insights into qualitative differences in narrative developmental feedback provided to women and men. To the best of our knowledge, our study is the first to do so, and our findings relate to, and further, current scholarship in several ways. First, a key finding of extant scholarship is that women leaders are less likely to receive accurate task-related performance feedback, and more likely to receive feedback focused on interpersonal conduct (Bear et al., 2017; Biernat et al., 2012). We find a similar emphasis in forward-focused developmental feedback provided to women (Aggregate Theoretical Dimension 3), illustrating how normative expectations about women's communal behaviors (Eagly \& Karau, 2002) also inform advice given to women leaders about how they should develop. In contrast, while men were not advised to develop the same level of interpersonal care, they were also not particularly directed towards agentic task-focused behaviors, as extant research would imply (Heilman \& Okimoto, 2007); instead, they were given a mandate to be agentic particularly in pursuing their leadership ambitions. In other words, whereas women were told to be interpersonally sensitive, and to focus on getting along with colleagues, men were advised to be ambitious and agentic in fulfilling their leadership potential and, ultimately, in claiming their space as a leader. This pattern presents a 
more wide-ranging and nuanced perspective on the distinction between task (male) and interpersonal (female) behavior discussed widely in research on gender bias in performance feedback (Bear et al., 2017), suggesting that a specific form of agency related leadership aspiration is disproportionately encouraged in male leaders.

Studies about leadership potential and career aspirations are also pertinent to interpreting these findings. Like others, we find that women's leadership potential can be under-rated (Cochran 1999, in Ely et al., 2011; Ibarra \& Obodaru, 2009); despite achieving equal performance ratings, women political leaders were less likely to receive feedback recognizing their leadership potential to the same extent and encouraging them to develop leadership ambition. This has far-reaching implications, as not being identified as having leadership potential can potentially hamper women's long-term career and leadership aspirations (Hoobler, Lemon, \& Wayne, 2011; Steffans et al., 2017).

Our findings also extend Bear et al.'s (2017) conceptual model of gender bias in performance feedback, by demonstrating that developmental feedback is gendered in ways that go beyond the tension posed by agency and communion, widely documented in psychological literature (Eagly \& Heilman, 2016; Heilman \& Okimoto, 2007). More specifically, we argue that feedback about being operational (rather than strategic: Aggregate Theoretical Dimension 1) and being resilient (rather than proactively influencing: Aggregate Theoretical Dimension 2) is likely to interfere with women's ability to develop as a leader, particularly in terms of progressing from middle to senior leadership ranks. Our findings contribute to scholarship by charting specific novel dimensions of gender bias, pertinent to developmental, rather than performance, feedback processes.

Broader scholarship on gender and leadership sheds light into the significance of these additional aspects of gender-bias pertaining to vision-setting and politics. Regarding visionary strategic skills (Aggregate Theoretical Dimension 1), we surmise that two mechanisms could 
underpin the different advice provided to women. First, as Ibarra and Obodaru (2009) speculate, women might perceive that they are granted less license to take risks, as they generally lack the presumption of competence afforded to male peers; an emphasis on technical detail could explain women's perceived shortage in visionary skills in their study of 360-degree numerical evaluations. Our findings lend empirical support to this explanation: feedback directing women to develop expertise and to focus on operational detail suggests that raters may perceive it more important that women demonstrate technical competence, rather than visionary skill. A complementary mechanism might also be the gender-typing of vision-setting as a more masculine managerial sub-role, as evidenced by Atwater et al. (2004); this would explain why men are encouraged to adopt a strategic mindset more often than women. However, progression into senior roles requires moving beyond a narrow focus on technical expertise, to incorporate strategic perspectives in decision-making (Lord \& Hall, 2005; Shipman, Byrne \& Mumford, 2010; Vinnicombe et al., 2018). Feedback advising women to develop technical skills is therefore likely to direct them along a leadership path that is less useful and ultimately detrimental in confining women to become 'technical experts' rather than 'visionary strategists'. In contrast, feedback to men encouraged them to shape the future by developing visionary skills and focusing on personal and broader strategic long-term agendas.

Furthermore, prior work suggested that women are more reluctant or conflicted about engaging in workplace politics (Doldor, Anderson, \& Vinnicombe, 2013; Mainiero, 1994; Mackenzie Davies, 2008; Perrewe \& Nelson, 2004; Buchanan, 2008; Wyatt \& Silvester, 2015). Our findings (Aggregate Theoretical Dimension 2) extend this work by demonstrating how such attitudes could be shaped by developmental feedback that encourages male and female leaders to navigate organizational politics differently (proactively vs defensively). Yet, the importance of political skill in leadership roles is widely documented (Ammeter, Douglas, 
Gardner, Hochwarter \& Ferris, 2002; Buchanan, 2016) and a more proactive approach to politics sets apart mid-level leaders from senior ones (Doldor, 2017). In sum, we demonstrate that developmental feedback is less likely to direct women towards nurturing visionary and political skills required for senior leadership roles (Day \& Dragoni, 2015). These differences can have potent effects in obstructing or enabling women's leadership development, as qualitative feedback is more likely to lead to behavioral developmental changes, compared to numerical performance scores (Brutus, 2010; Kabins, 2016). In the context of developmental feedback, these differences suggest that women may receive ineffective advice; or to use Eagly and Carli's (2007) labyrinth metaphor, they may be directed along leadership paths that are more likely to lead to a dead-end.

Our findings raise the broader question of what constitutes good quality developmental feedback for women leaders? Literature suggests that constructive, challenging, specific and actionable feedback is useful to leadership development (Day, 2001; DeRue \& Wellman, 2009; Ely et al., 2011), and can mitigate the unwanted effects of gender biases (Bear et al., 2017). Feedback encouraging men to be proactive about managing politics (e.g. to build their networks, influence behind the scenes) is arguably more action-oriented than feedback urging women to develop a thicker skin and be less sensitive (Aggregate Theoretical Dimension 2). Additionally, feedback advising men to display more confidence in specific areas (e.g. public speaking) is arguably more actionable than feedback depicting women as inherently flawed for lacking confidence (Gist \& Mitchell, 1992: Aggregate Theoretical Dimension 3). Yet, feedback advising women to enhance technical expertise in certain areas and to learn how to better accomplish goals (Aggregate Theoretical Dimension 1) is arguably also specific, challenging and actionable, but nevertheless unhelpful from a leadership progression perspective. Such feedback might help women perform better in their current role, but does not set them up for the development required to take on more senior 
leadership roles. Moreover, feedback that focuses on the task and specific behaviors (e.g. invest more time building networks with $\mathrm{X}$ group) has more positive effects on performance (Kluger \& DeNisi, 1996; Smither \& Walker, 2004), and arguably on leadership development, compared to feedback that focuses on recipient's broad traits or characteristics (e.g. be more confident, be less emotive). Therefore, our findings extend scholarship on feedback, gender and leadership (Bear et al., 2017) by demonstrating that in order to be conducive to women's leadership development, feedback needs to be actionable, specific and constructive, while also preserving a focus on increasingly sophisticated leadership skills and behaviors (rather than only on skills for the current role) (Lord \& Hall, 2005).

\section{Topic modeling and qualitative leadership research}

Our second contribution to scholarship stems from our methodology. In using topic modeling to complement traditional qualitative analyses we not only test the methodology as a novel and beneficial way to sort a large number of feedback comments into a manageable framework, but as a potentially advantageous method for leadership researchers to use with a wide range of other types of qualitative data. In the case of our study, topic modeling was used to create an initial framework to sort narrative feedback, which remains underutilized as a source of naturally occurring data in organizational settings. As traditional methods of qualitative analysis require extensive time and resources to sort and code such data manually (Speer, 2018), being able to analyze qualitative feedback more manageably is not only time and resource efficient; it also provides a valuable means to theorize about leadership development, where, unlike quantitative ratings, feedback is targeted at individuals and their future trajectory, rather than decision makers (Brutus, 2010). As such, qualitative narrative feedback can provide a unique insight into the contextualized expectations of observers. 
Using a Structural Topic Model (Roberts et al., 2014) was particularly useful for our analysis of feedback because it enabled us to examine how the content of feedback topics varied for male and female leaders by providing an initial organizing framework. Scholars immersed in early stages of qualitative analysis with traditional thematic approaches often feel "lost" in the data as they seek to distill first order codes (Gioia, Corley \& Hamilton, 2013). Topic modeling provides a time effective and parsimonious way of identifying an initial organizing framework for vast amounts of qualitative data (Schmiedel et al., 2018) and could thus be a valuable methodological tool for scholars seeking to provide insights about leadership phenomena through exploratory research (Antonakis, 2017). Therefore, we address calls for organizational scholars to adopt this form of analysis and also demonstrate how it can be combined with traditional methods of qualitative analyses to uncover important nuances in the data (Schmiedel et al., 2018).

\section{Limitations and Future Research}

The current study is not without limitations. First, we were not able to establish the extent that the feedback provided in this study was politically motivated. Political behavior in organizations has been defined as the "management of shared meaning in such a way as to produce desired, self-serving responses or outcomes" (Ferris, Fedor \& King, 1994, pp. 4; Silvester, 2008). Qualitative feedback arguably provides an opportunity for observers to manage shared meanings about individuals' leadership development, driven by self-serving motives such as protecting group or personal resources, managing conflict and maintaining power (Bear et al., 2017; Longnecker, Sims \& Gioia, 1987; Rosen et al., 2017). Using feedback as a self-serving tool is particularly likely in the political context of this study, where individuals are competing with others within and across different political parties in an environment where what constitutes good performance is contested (Silvester \& Wyatt, 2018). Future research therefore needs to explore the inherently political nature of feedback 
and development more generally. Future research could also explore similarities and differences between feedback processes in political and corporate environments; our unique sample of political leaders limits generalizability to other organizational settings.

Our findings are also relevant to an emerging literature on leadership identity construction (DeRue \& Ashford, 2010; Ely at al., 2011; Marchiondo, Myers \& Kopelman, 2015; Epitropaki, Kark, Mainemelis \& Lord, 2017). Feedback can be a vehicle for social cues relevant to leadership identity construction (Day \& Dragoni, 2015; Ely et al., 2011; Lord \& Hall, 2005), through which a leader comes to see herself, and be seen by others, as a leader (DeRue \& Ashford 2010). Narrative feedback may capture the ‘day-to-day' micro interactions between leaders and followers that speak to how leader identities might be granted differently to women and men through subtle cues that permeate the interplay between developing a belief in self as a leader and acceptance by others as a leader.

DeRue \& Ashford (2010) posit that in order to support leadership identity construction, grants need to be clear, credible and public. Our findings suggest that highquality grants in feedback processes aimed at supporting leadership development are those that provide both content relevant to leadership identities, and actionable advice that gives individuals a roadmap towards developing those identities. Future research could further examine how feedback might provide different roadmaps towards leadership identity construction for male and female leaders and their impact on subsequent leadership journeys. More specifically, what constitutes useful feedback for women and men that helps them develop their identity as a leader and progress their leadership ambitions? This would call for data both on what feedback is imparted, and how the feedback is received and incorporated in leadership identity construction processes by the recipients, to capture both claiming and granting aspects (DeRue and Ashford, 2010). A key limitation in our data set is that we were also unable to monitor how political leaders reacted to the feedback they were provided, and 
whether they internalized the messages conveyed by adjusting cognitive, emotional and behavioral responses. It is possible for example, that politically skilled leaders may be more aware of, and able to sense, politically motivated content in feedback enabling them to filter which messages they attend to accordingly. Moreover, Bear et al. (2017) suggest that the way individuals react to feedback influences their likelihood of opting into leadership roles and how others perceive them. Longitudinal research that examines claiming and granting mechanisms inherent in the feedback process is therefore vital if we are to enhance knowledge of the implications of feedback for leadership identity construction.

Third, although we found topic modeling valuable for organizing the large number of feedback comments in our data, the method is not without limitations. Like many computerized methods of natural language processing, topic modeling employs what is known as a 'bag of words' technique, where information about the order of words is ignored. This means that nuances in the data may be overlooked, such as turns of phrase, colloquialisms or sarcasm. Removing highly used words (known as 'stop words'), also has the potential to alter meaning. Therefore, although topic modeling is an attractive means for sorting large amounts of qualitative data quickly, it should not be regarded as a 'quick fix' for identifying themes. As Schmiedel et al (2018, p. 20) point out, the algorithms play a "supporting role" to the decisions and subjective interpretations researchers must make, including choosing the number of topics, labelling and interpreting topic content. Ultimately, we urge researchers not to see topic modeling as an end in itself, but as a tool to organize qualitative data in ways that make it more manageable for human coders to explore themes in depth.

Finally, because politicians may have requested feedback from a relatively small pool of colleagues, it was not possible to collect information about the gender of respondents, to ensure their confidentiality. Existing research on quantitative ratings of performance has 
found that male raters favor males in both female and male dominated roles, and that male raters may be more likely to see women as incongruous with masculine roles (Koch, D’Mello $\&$ Sackett, 2015). Female leaders whose performance is evaluated by a higher number of women are also rated as more effective (Paustian-Underdahl, Slattery Walker \& Woehr, 2014). Therefore, future research should examine how the gender of feedback providers may influence narrative developmental feedback.

\section{Practical implications}

A current trend in workforce diversity management is training that attempts to increase awareness of the common biases individuals may hold (unconscious bias training: Atewologun, Cornish \& Tresh, 2018). These initiatives are often considered a 'silver bullet' to address discrimination and unfair treatment in organizations (Williamson \& Foley, 2018) and improve gender balance in top leadership (Kossek, Su, \& Wu, 2017). However, mere awareness of bias is unlikely to improve diversity outcomes without addressing how bias translates into action across specific organizational processes (Noon, 2018). Our findings suggest that developmental feedback is a potential vehicle for (conscious or unconscious) biases to manifest in the workplace. Therefore, monitoring, and potentially recalibrating, the focus of messages relevant to leadership development in feedback processes would not only help the feedback recipients develop increasingly sophisticated leadership skills required for senior leadership; it would also shape how other gate-keepers perceive them (e.g. promotion panels who have sight of qualitative feedback received by these individuals, and use such data in their decision-making). We offer a tangible indication of how behavior can be changed to provide more gender inclusive developmental feedback and genuinely support women in developing the skills required for senior leadership: providing both actionable and challenging 
feedback, as well as focusing on long-term strategic vision and a pro-active approach to managing workplace politics.

\section{Conclusion}

Cheryl Sandberg's (2013) now famous advice for working women to 'lean in' has attracted criticism for its emphasis on women's individual agency and its relative neglect of structural gender inequalities. 'Leaning in' is a series of choices shaped, at least partially, by the organizational landscape women navigate. Endemic organizational processes such as feedback can insidiously send different messages to men and women about what they should lean towards and how they should do it. Our findings suggest that women leaders are directed down the path to become cheerleaders: they are told to develop technical skills and to be confident, but ultimately to stay on the side-lines playing an enthusiastic but supportive role for others. In contrast, men's feedback directs them towards becoming dignified statesmen, influential in articulating their vision, versed in the art of politics and comfortable in claiming their leadership space. To make the 'leaning in' process more equitable, women need feedback that provides the developmental roadmap they need to become stateswomen, rather than the cheerleaders for more powerful statesmen.

\section{References}

Adler, S., Campion, M., Colquitt, A., Grubb, A., Murphy, K., Ollander-Krane, R., \& Pulakos, E. D. (2016). Getting rid of performance ratings: Genius or folly? A debate. Industrial and Organizational Psychology, 9(2), 219-252.

Aguinis, H., \& Solarino, A. M. (2019). Transparency and replicability in qualitative research: The case of interviews with elite informants. Strategic Management Journal. doi: $10.1002 / \mathrm{smj} .3015$

Airoldi, E. M., \& Bischof, J. M. (2016). Improving and evaluating topic models and other models of text. Journal of the American Statistical Association, 111(516), 1381-1403. 
Ammeter, A. P., Douglas, C., Gardner, W. L., Hochwarter, W. A., \& Ferris, G. R. (2002). Toward a political theory of leadership. Leadership Quarterly, 13 (6), 433-435.

Antonakis, J. (2017). On doing better science: From thrill of discovery to policy implications, The Leadership Quarterly, 28(1), 5-21.

Ashford, S. J. (1986). Feedback-seeking in individual adaptation: A resource perspective. Academy of Management journal, 29(3), 465-487.

Ashford, S. J., \& Cummings, L. L. (1983). Feedback as an individual resource: Personal strategies of creating information. Organizational Behavior and Human Performance, 32(3), 370-398.

Ashford, S. J., \& Tsui, A. S. (1991). Self-regulation for managerial effectiveness: The role of active feedback seeking. Academy of Management Journal, 34(2), 251-280.

Atewologun, D., Cornish, T. and Tresh, F. (2018). Unconscious bias training: An assessment of the evidence for effectiveness. Equality and Human Rights Commission, UK.

Avolio, B. J. (2005). Leadership development in balance: Made/born. Mahwah, NJ: Lawrence Erlbaum Associates

Banks, G. C., Woznyj, H. M., Wesslen, R. S., \& Ross, R. L. (2018). A Review of best practice recommendations for text analysis in $\mathrm{R}$ (and a user-friendly app). Journal of Business and Psychology, 33(4), 445-459.

Baum, C. F. (2008). Stata tip 63: Modeling proportions. Stata Journal, 8(2), 299-303.

Bear, J. B., Cushenbery, L., London, M., \& Sherman, G. D. (2017). Performance feedback, power retention, and the gender gap in leadership. The Leadership Quarterly, 28(6), 721-740.

Biernat, M., Fuegen, K., \& Kobrynowicz, D. (2010). Shifting standards and the inference of incompetence: Effects of formal and informal evaluation tools. Personality and Social Psychology Bulletin, 36(7), 855-868.

Biernat, M., Tocci, M. J., \& Williams, J. C. (2012). The language of performance evaluations: Gender-based shifts in content and consistency of judgment. Social Psychological and Personality Science, 3(2), 186-192.

Bjarnegård, E., \& Murray, R. (2018). Critical perspectives on men and masculinities in politics: Introduction. Politics \& Gender, 14(2), 264-265.

Blei, D. M. (2012). Surveying a suite of algorithms that offer a solution to managing large document archives. Communication of the ACM, 55(4), 77-84.

Blei, D. M., Ng, A. Y., \& Jordan, M. I. (2003). Latent dirichlet allocation. Journal of Machine Learning Research, 3(Jan), 993-1022.

Bollich, K. L., Johannet, P. M., \& Vazire, S. (2011). In search of our true selves: Feedback as a path to self-knowledge. Frontiers in Psychology, 2, 312. 
Bracken, D. W., Rose, D. S., \& Church, A. H. (2016). The evolution and devolution of 360 feedback. Industrial and Organizational Psychology, 9(4), 761-794.

Brown, M., Kulik, C. T., \& Lim, V. (2016). Managerial tactics for communicating negative performance feedback. Personnel Review, 45(5), 969-987.

Brutus, S. (2010). Words versus numbers: A theoretical exploration of giving and receiving narrative comments in performance appraisal. Human Resource Management Review, 20(2), $144-157$.

Buchanan, D. (2008). You Stab My Back, I'll Stab Yours: Management Experience and Perceptions of Organization Political Behaviour. British Journal of Management, 19(1), 49-65.

Buchanan, D. (2016). Rats in the shadows: researching organizational politics. In VigodaGadot, E. \& Drory, A. (eds) Handbook of Organizational Politics, Looking Back and to the Future, (pp 340 - 368) Cheltenham: Edward Elgar.

Cassell, C., Cunliffe, A. L., \& Grandy, G. (Eds.). (2017). The SAGE Handbook of Qualitative Business and Management Research Methods. London Sage.

Catalyst (2018). Women CEOs of the $S \& P$ 500. https://www.catalyst.org/knowledge/womenceos-sp-500 Accessed 02 July 2019

Chang, J., Gerrish, S., Wang, C., Boyd-Graber, J. L., \& Blei, D. M. (2009). Reading tea leaves: How humans interpret topic models. In Advances in Neural Information Processing Systems. 288-296.

Childs, S., \& Hughes, M. (2018). "Which Men?" How an Intersectional Perspective on Men and Masculinities Helps Explain Women's Political Underrepresentation. Politics \& Gender, 14(2), 282-287.

Corley, K. G., \& Gioia, D. A. (2004). Identity ambiguity and change in the wake of a corporate spin-off. Administrative Science Quarterly, 49(2), 173-208.

Dacin, M. T., Munir, K., \& Tracey, P. (2010). Formal dining at Cambridge colleges: Linking ritual performance and institutional maintenance. Academy of Management Journal, 53(6), $1393-1418$.

Day, D. V. (2000). Leadership development: A review in context. The Leadership Quarterly, 11(4), 581-613.

Day, D. V., \& Dragoni, L. (2015). Leadership development: An outcome-oriented review based on time and levels of analyses. Annual Review of Organizational Psychology and Organizational Behavior, 2(1), 133-156.

Day, D. V., Fleenor, J. W., Atwater, L. E., Sturm, R. E., \& McKee, R. A. (2014). Advances in leader and leadership development: A review of 25 years of research and theory. The Leadership Quarterly, 25(1), 63-82. 
DeRue, D. S., \& Wellman, N. (2009). Developing leaders via experience: the role of developmental challenge, learning orientation, and feedback availability. Journal of Applied Psychology, 94(4), 859-875.

DeRue, D. S., \& Ashford, S. J. (2010). Who will lead and who will follow? A social process of leadership identity construction in organizations. Academy of Management Review, 35(4), 627647.

DeRue, D.S., Nahrgang, J. D., Hollenbeck, J. R., \& Workman, K. (2012). A quasi-experimental study of after-event reviews and leadership development. Journal of Applied Psychology, 97(5), 997-1015.

Doldor, E. (2017). From Politically Naïve to Politically Mature: Conceptualizing Leaders' Political Maturation Journey. British Journal of Management, 28(4), 666-686.

Doldor, E., Anderson, D. \& Vinnicombe, S. (2013). Refining the Concept of Political Will: A Gender Perspective. British Journal of Management, 24, 414-427.

Doldor E., Silvester J., \& Atewologun D. (2017). Qualitative Methods in Organizational Psychology In W.S. Rogers \& C. Willig (Eds) The SAGE Handbook of Qualitative Research in Psychology (pp. 520-540). London: Sage.

Eagly, A. H. (1987). Reporting sex differences. American Psychologist, 42(7), 756-757.

Eagly AH and Carli LL (2007) Women and the labyrinth of leadership. Harvard Business Review 85(9): 62-71

Eagly, A. \& Heilman, M. (2016). Gender and leadership: Introduction to the Special Issue. The Leadership Quarterly, 27(3), 349-353.

Eagly, A. H., \& Karau, S. J. (2002). Role congruity theory of prejudice toward female leaders. Psychological Review, 109(3), 573-598.

Edmondson, A. C., \& McManus, S. E. (2007). Methodological fit in management field research. Academy of Management Review, 32(4), 1155-1179.

Ely, R. J., Ibarra, H., \& Kolb, D. M. (2011). Taking gender into account: Theory and design for women's leadership development programs. Academy of Management Learning \& Education, 10(3), 474-493.

Epitropaki, O., Kark, R., Mainemelis, C., \& Lord, R. G. (2017). Leadership and followership identity processes: A multilevel review. The Leadership Quarterly, 28(1), 104-129.

Ferris, G. R., Fedor, D. B, \& King, T. R. (1994). A political conceptualization of managerial behaviour. Human Resource Management Review, 4, 1-34.

Ferstl, K. L., \& Bruskiewicz, K. T. (2000, April). Self- other agreement and cognitive reactions to multirater feedback. Paper presented at the 15th annual conference of the Society of Industrial and Organizational Psychology, New Orleans, LA. 
Fleiss, J. L. (1971). Measuring nominal scale agreement among many raters. Psychological Bulletin (76), 378-382.

Gioia, D. A., Corley, K. G., \& Hamilton, A. L. (2013). Seeking Qualitative Rigor in Inductive Research: Notes on the Gioia Methodology. Organizational Research Methods, 16(1), 15-31.

Gist, M. E., \& Mitchell, T. R. (1992). Self-efficacy: A theoretical analysis of its determinants and malleability. Academy of Management Review, 17(2), 183-211.

Halpern, D. F. (2004). The development of adult cognition: Understanding constancy and change in adult learning. In D. A. Day, S. J. Zaccaro, \& S. M. Halpin (Eds.), Leader development for transforming organizations (pp. 125-152). Mahwah, NJ: Erlbaum.

Hannigan, T., Haans, R.F.J., Vakili, K., Tchalian, H., Glaser, V., Wang, M., Kaplan, S., \& Jennings, D. (2019). Topic modelling in management research: Rendering new theory from textual data. Academy of Management Annals, doi: 10.5465/annals.2017.0099

Heilman, M. E., \& Okimoto, T. G. (2007). Why are women penalized for success at male tasks?: The implied communality deficit. Journal of Applied Psychology, 92(1), 81-92.

Hoobler, J. M., Wayne, S. J., \& Lemmon, G. (2009). Bosses' Perceptions of Family-Work Conflict and Women's Promotability: Glass Ceiling Effects. Academy Of Management Journal, 52(5), 939-957

Ibarra, H., \& Obodaru, O. (2009). Women and the vision thing. Harvard Business Review, 87(1), 62-70.

Kabins, A. (2016). Why the qualms with qualitative? Utilizing qualitative methods in $360^{\circ}$ feedback. Industrial and Organizational Psychology, 9(4), 806-810.

Kanfer, R., \& Ackerman, P. L. (1989). Motivation and cognitive abilities: An integrative/aptitude-treatment interaction approach to skill acquisition. Journal of Applied Psychology, 74(4), 657-690.

King, E. B., Botsford, W., Hebl, M. R., Kazama, S., Dawson, J. F., \& Perkins, A. (2012). Benevolent sexism at work: Gender differences in the distribution of challenging developmental experiences. Journal of Management, 38(6), 1835-1866

Kluger, A. N., \& DeNisi, A. (1996). The effects of feedback interventions on performance: A historical review, a meta-analysis, and a preliminary feedback intervention theory. Psychological Bulletin, 119(2), 254-284.

Koch, A. J., D'mello, S. D., \& Sackett, P. R. (2015). A meta-analysis of gender stereotypes and bias in experimental simulations of employment decision making. Journal of Applied Psychology, 100(1), 128-161.

Kossek, E. E., Su, R., \& Wu, L. (2017) “Opting Out” or "Pushed Out”? Integrating Perspectives on Women's Career Equality for Gender Inclusion and Interventions. Journal of Management, 43(1), 228-254. 
Li, N., Harris, T. B., Boswell, W. R., \& Xie, Z. (2011). The role of organizational insiders' developmental feedback and proactive personality on newcomers' performance: An interactionist perspective. Journal of Applied Psychology, 96(6), 1317-1327.

Longnecker, C. O., Sims, H. P., \& Gioia, D. A. (1987). Behind the , ask: The politics of employee appraisal. Academy of Management Perspectives, 1(3), 183-193.

Lord, R. G., \& Hall, R. J. (2005). Identity, deep structure, and the development of leadership skill. The Leadership Quarterly, 16 (4), 591-615.

Lyness, K. S., \& Heilman, M. E. (2006). When fit is fundamental: Performance evaluations and promotions of upper-level female and male managers. Journal of Applied Psychology, 91(4), $777-785$.

Mackenzie Davey, K. (2008). Women's accounts of organizational politics as a gendering process. Gender, Work and Organization, 15(6), 650-671.

Maki, R. H. (1998). Test predictions over text material. In D. J. Hacker, J. Dunlosky, \& A. C. Graesser (Eds.), Metacognition in Theory and Practice (pp. 117-144). Mahwah: Lawrence Erlbaum Associates.

Mantere, S., Schildt, H. A., \& Sillince, J. A. (2012). Reversal of strategic change. Academy of Management Journal, 55(1), 172-196.

Marchiondo, L. A., Myers, C. G., \& Kopelman, S. (2015). The relational nature of leadership identity construction: How and when it influences perceived leadership and decisionmaking. The Leadership Quarterly, 26(5), 892-908.

Markham, S. E., Markham, I. S., \& Smith, J. W. (2015). At the crux of dyadic leadership: Self-other agreement of leaders and direct reports-Analyzing 360-degree feedback. The Leadership Quarterly, 26(6), 958-977.

Maxwell, J. A. (2010). Using numbers in qualitative research. Qualitative Inquiry, 16(6), 475482.

McCauley, C. D., \& Van Velsor, E. (Eds.). (2004). The 'Center for Creative Leadership Handbook of Leadership Development. San Francisco, CA: Jossey-Bass.

Mildenberger, M., \& Tingley, D. (2017). Beliefs about Climate Beliefs: The importance of second-order opinions for climate politics. British Journal of Political Science, 1-29.

Mimno, D., Wallach, H. M., Talley, E., Leenders, M., \& McCallum, A. (2011, July). Optimizing semantic coherence in topic models. In Proceedings of the conference on empirical methods in natural language processing (pp. 262-272). Association for Computational Linguistics.

Morrison, R. F., \& Brantner, T. M. (1992). What enhances or inhibits learning a new job? A basic career issue. Journal of Applied Psychology, 77(6), 926-940. 
Neuman, W. L. (2006). Social Research Methods: Qualitative and Quantitative Approaches. Boston, MA: Pearson Education.

Noon, M. (2018). Pointless diversity training: Unconscious bias, new racism and agency. Work, Employment and Society, 32(1), 198-209.

Parry, K., Mumford, M.D., Bower, I., \& Watts, L.L. (2014). Qualitative and historiometric methods in leadership research: A review of the first 25 years of The Leadership Quarterly. The Leadership Quarterly, 25(1), 132-151.

Paustian-Underdahl, S. C., Walker, L. S., \& Woehr, D. J. (2014). Gender and perceptions of leadership effectiveness: A meta-analysis of contextual moderators. Journal of Applied Psychology, 99(6), 1129-1145.

Perrewe, P. L. and Nelson, D. L. (2004). Gender and Career Success: The Facilitative Role of Political Skill. Organizational Dynamics, 33, 366-378.

Piepenbrink, A., \& Gaur, A. S. (2017). Topic models as a novel approach to identify themes in content analysis. In Academy of Management Best Paper Proceedings (Vol. 2017, No. 1, p. 16). Briarcliff Manor, NY 10510: Academy of Management.

Roberts, M., Stewart, B., \& Tingley, D. (2014). Stm: R package for structural topic models. Journal of Statistical Software. doi: 10.18637/jss.v000.i00

Roberts, M. E., Stewart, B. M., Tingley, D., Lucas, C., Leder-Luis, J., Gadarian, S. K., \& Rand, D. G. (2014). Structural topic models for open-ended survey responses. American Journal of Political Science, 58(4), 1064-1082.

Rosen, C. C., Kacmar, K. M., Harris, K. J., Gavin, M. B., \& Hochwarter, W. A. (2017).

Workplace politics and performance appraisal: A two-study, multilevel field investigation. Journal of Leadership \& Organizational Studies, 24(1), 20-38.

Sandberg, C. (2013). Lean In: Women, Work, and the Will to Lead. WH Allen, New York.

Schein, V. E. (2001). A global look at Psychological barriers of women's progress in management. Journal of Social Issues, 57(4), 675-688.

Schein, V. E., Mueller, R., Lituchy, T., \& Liu, J. (1996). Think manager-think male: A global phenomenon?. Journal of Organizational Behavior, 17(1), 33-41.

Schmiedel, T., Muller, O., \& vom Brocke, J. (2018). Topic modeling as a strategy of inquiry in organizational research: A tutorial with an application examples on organizational culture. Organizational Research Methods, 28, 1094-4281.

Schneider, M. C., Holman, M. R., Diekman, A. B., \& McAndrew, T. (2016). Power, conflict, and community: How gendered views of political power influence women's political ambition. Political Psychology, 37(4), 515-531. 
Schofield, A., \& Mimno, D. (2016). Comparing apples to apple: The effects of stemmers on topic models. Transactions of the Association for Computational Linguistics, 4, 287-300.

Scott, K. A., \& Brown, D. J. (2006). Female first, leader second? Gender bias in the encoding of leadership behavior. Organizational Behavior and Human Decision Processes, 101(2), 230242.

Shipman, A.S., Byrne, C.L., \& Mumford, M.D. (2010). Leader vision formation and forecasting: The effects of forecasting extent, resources, and timeframe. The Leadership Quarterly, 21(3), 439-456.

Silvester, J. (2008). The good, the bad and the ugly: Politics and politicians at work. International Review of Industrial and Organizational Psychology, 23, 107.

Silvester, J., \& Menges, C. (2011). The political mentoring toolkit.

http://openaccess.city.ac.uk/444/2/Silvester\%20\%20Menges\%20(2011)\%20Political_Mentori ng_Toolkit.pdf Accessed 01 June 2019

Silvester, J., Wyatt, M., \& Randall, R. (2014). Politician personality, Machiavellianism, and political skill as predictors of performance ratings in political roles. Journal of Occupational and Organizational Psychology, 87(2), 258-279.

Silvester, J., \& Wyatt, M. (2015). Developing strong and diverse political leaders. The Psychologist, 28(5), 368-371.

Silvester, J., \& Wyatt, M. (2018). Political effectiveness at work. In D.S. Ones, N. Anderson, H.K. Sinangil, \& C. Viswesvaran, (Eds.), Handbook of Industrial Work and Organizational Psychology, Volume 3. London: Sage.

Smith, D. G., Rosenstein, J. E., Nikolov, M. C., \& Chaney, D. A. (2018). The Power of Language: Gender, Status, and Agency in Performance Evaluations. Sex Roles, 80(3-4), 159171

Smither, J. W., \& Walker, A. G. (2004). Are the characteristics of narrative comments related to improvement in multirater feedback ratings over time?. Journal of Applied Psychology, 89(3), 575.

Speer, A. B. (2018). Quantifying with words: An investigation of the validity of narrativederived performance scores. Personnel Psychology, 71(3), 299-333.

Steffens, N. K., Fonseca, M. A., Ryan, M. K., Rink, F. A., Stoker, J. I., \& Pieterse, A. N. (2018). How feedback about leadership potential impacts ambition, organizational commitment, and performance. The Leadership Quarterly, 29(6), 637-647

Strauss, A. L., \& Corbin, J. (1998). Basics of Qualitative Research (Vol. 2). Thousand Oaks, CA: Sage.

Taddy, M. (2012). On Estimation and Selection for Topic Models. Proceedings of the Fifteenth International Conference on Artificial Intelligence and Statistics, 22, 1184-1193. 
Tausczik, Y. R., \& Pennebaker, J. W. (2010). The psychological meaning of words: LIWC and computerized text analysis methods. Journal of Language and Social Psychology, 29(1), 24-54.

Thomas-Hunt, M. C., \& Phillips, K. W. (2004). When what you know is not enough: Expertise and gender dynamics in task groups. Personality and Social Psychology Bulletin, 30(12), 15851598 .

UNWomen. Facts and figures: Leadership and political participation. http://www.unwomen.org/en/what-we-do/leadership-and-political-participation/facts-andfigures Accessed 02 July 2019

Vinnicombe, S, Doldor, E., \& Sealy, R. (2018). Female FTSE Board Report 2018: Busy going nowhere with the executive pipeline. Cranfield University.

Wallach, H. M., Murray, I., Salakhutdinov, R., \& Mimno, D. (2009, June). Evaluation methods for topic models. In Proceedings of the 26th annual international conference on machine learning (pp. 1105-1112). ACM.

Williamson, S., \& Foley, M. (2018). Unconscious bias training: The 'silver bullet' for gender equity? Australian Journal of Public Administration, 77(3), 355-359.

Wilson, K. Y. (2010). An analysis of bias in supervisor narrative comments in performance appraisal. Human Relations, 63(12), 1903-1933.

Wyatt, M., \& Silvester, J. (2015). Reflections on the labyrinth: Investigating black and minority ethnic leaders' career experiences. Human Relations, 68(8), 1243-1269.

Yoon, H.G., Kim, H. Kim, C.O., \& Song, M. (2016). Opinion polarity detection in Twitter data combining shrinkage regression and topic modelling Journal of Informetrics, 10(2), 634-644.

Zhou, J. (2003). When the presence of creative coworkers is related to creativity: Role of supervisor close monitoring, developmental feedback, and creative personality. Journal of Applied Psychology, 88(3), 413-422. 


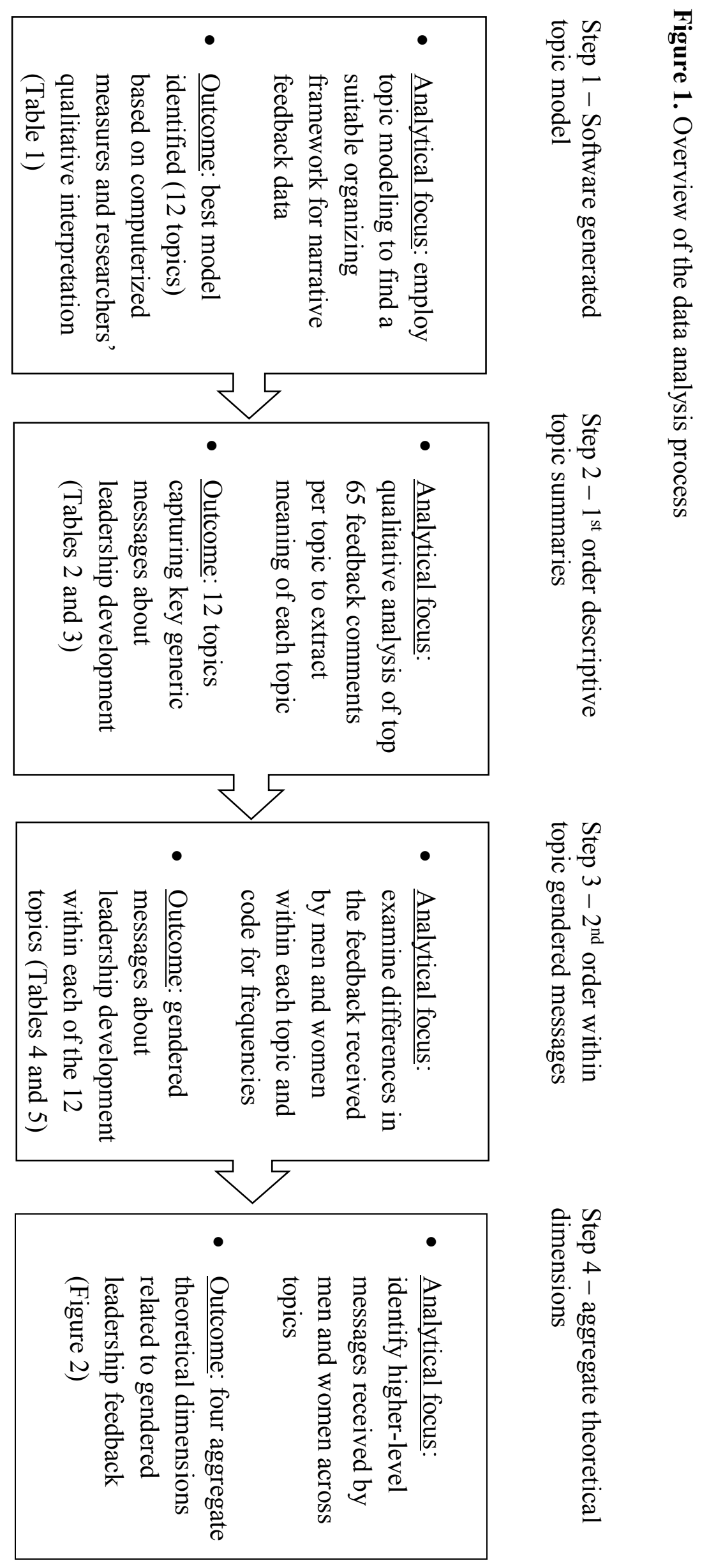



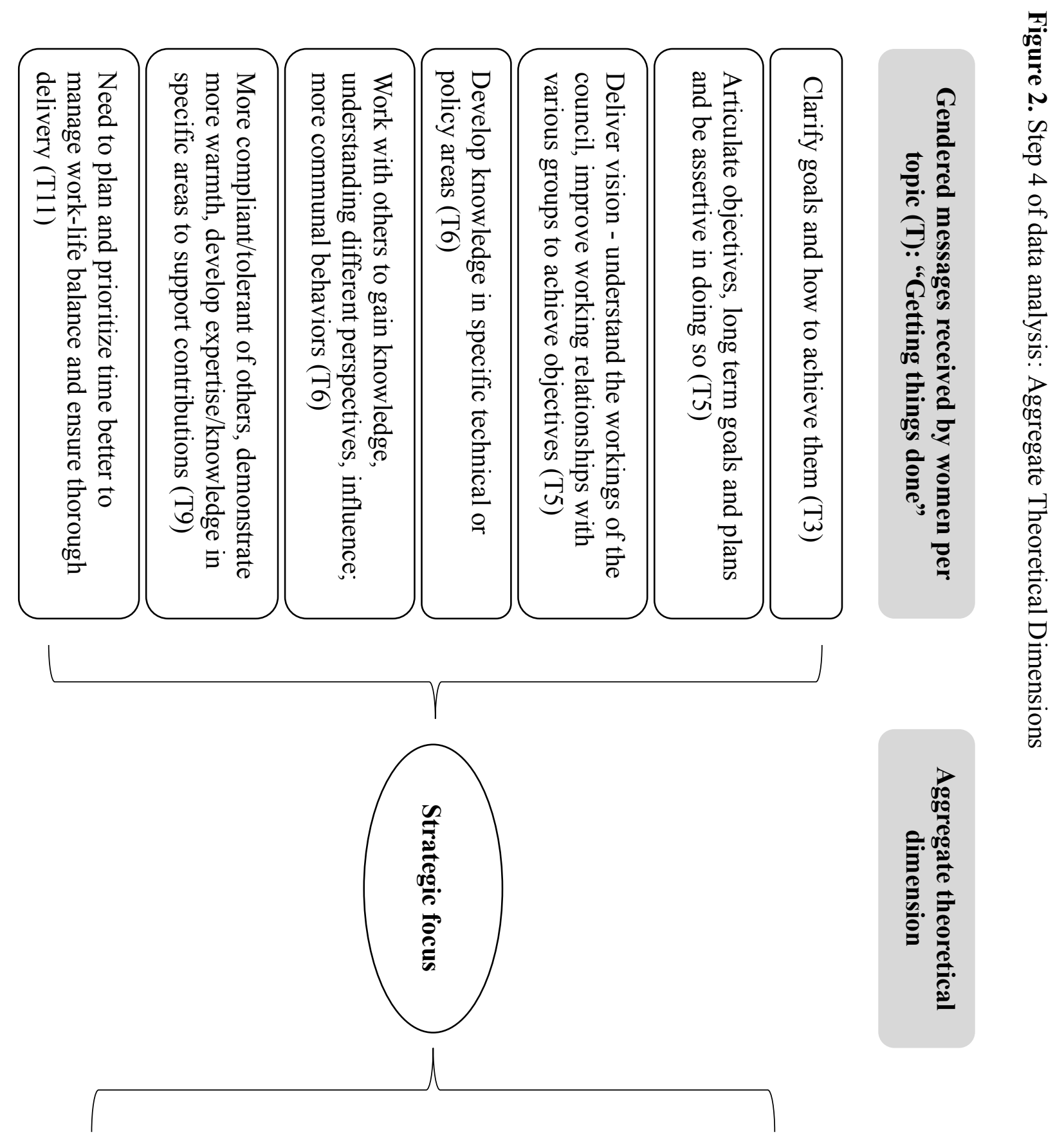

\begin{tabular}{|c|c|c|c|c|c|c|}
\hline 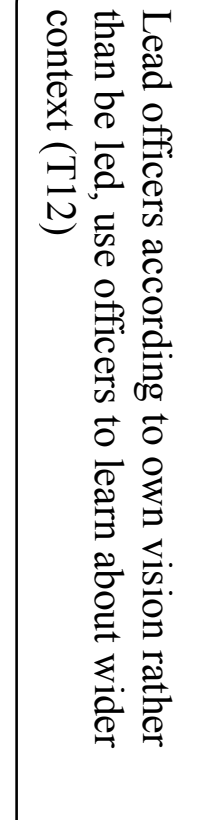 & 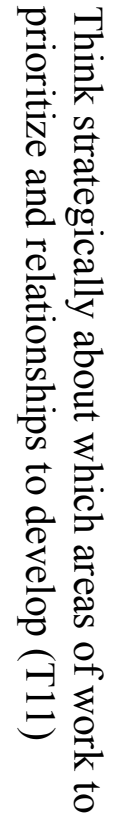 & 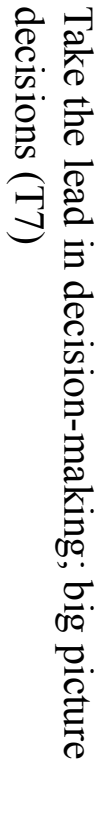 & 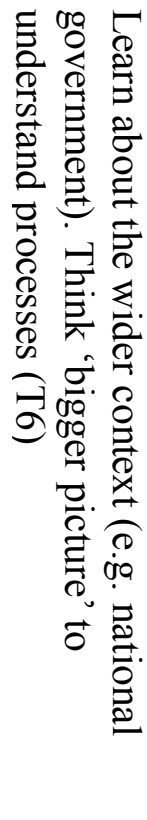 & 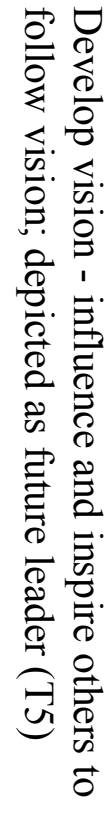 & 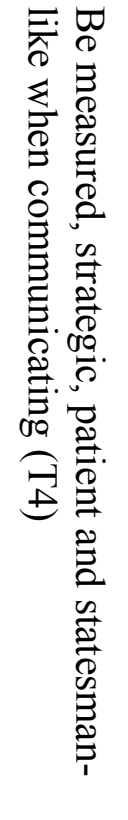 & 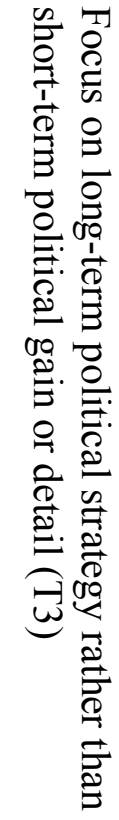 \\
\hline
\end{tabular}

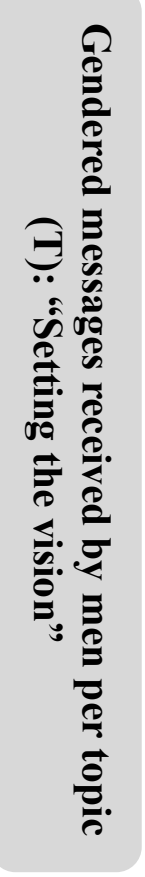



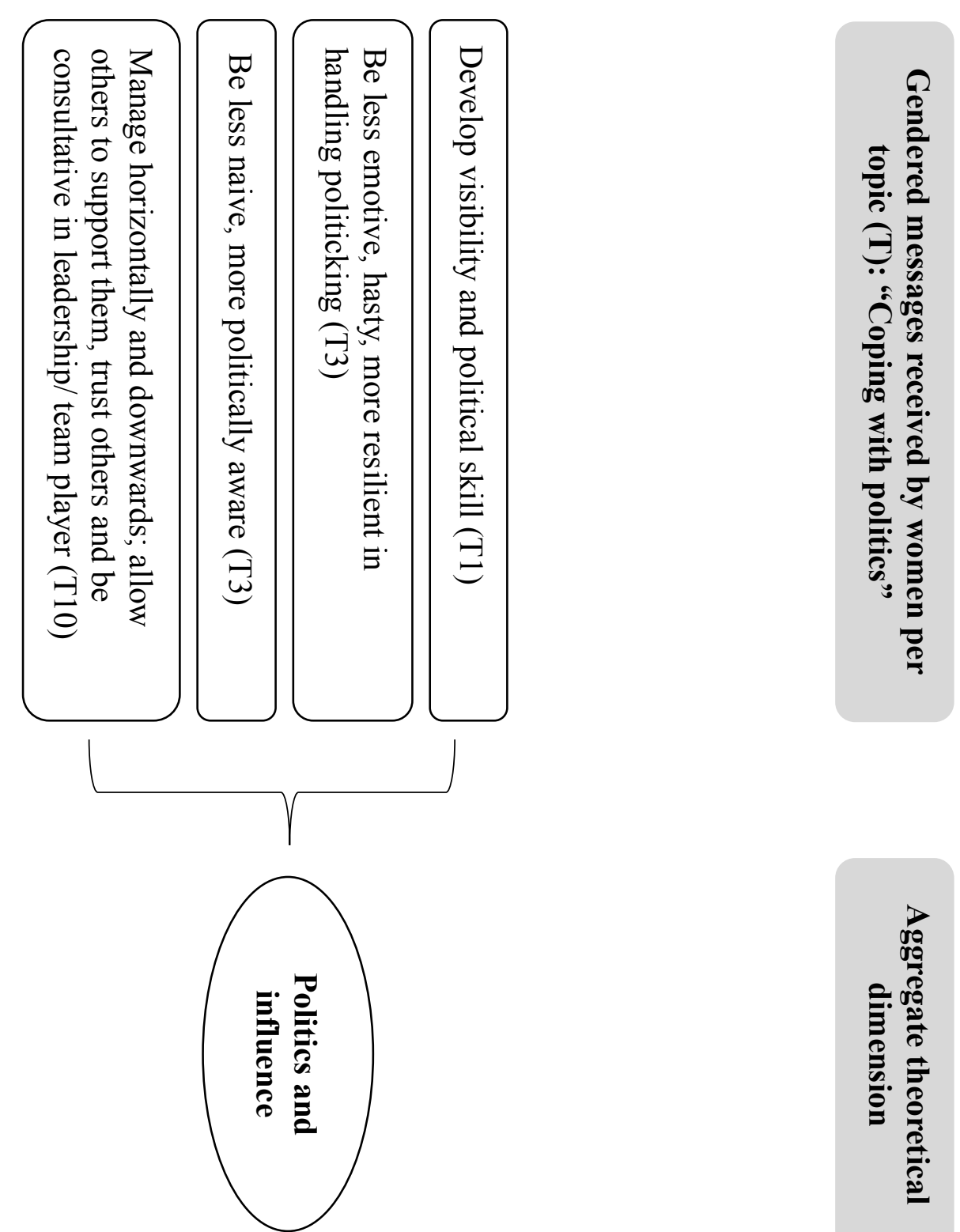

\begin{tabular}{|c|c|c|c|c|c|c|}
\hline 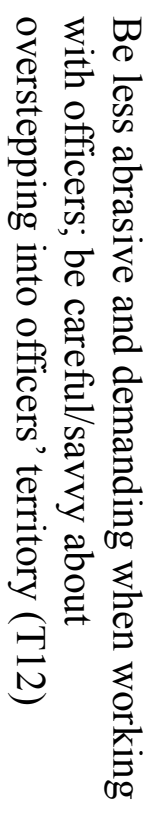 & 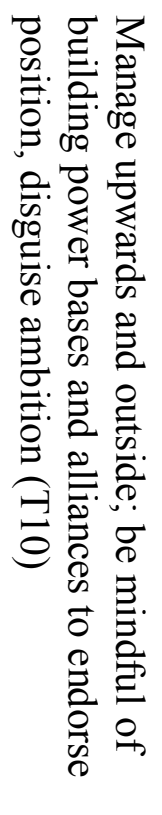 & 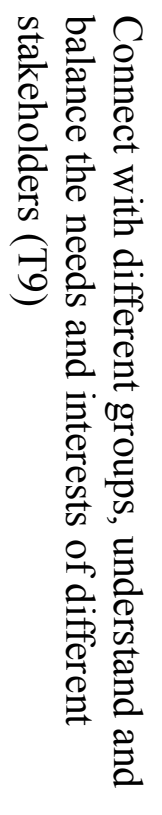 & 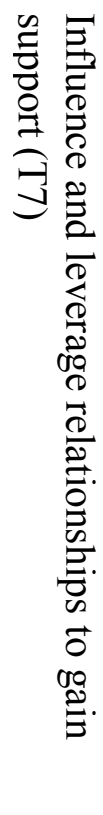 & 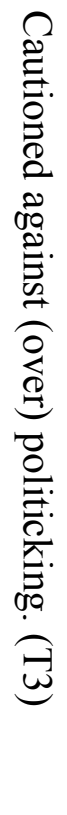 & 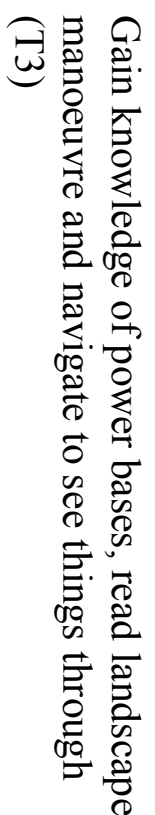 & 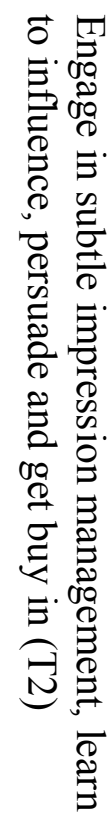 \\
\hline
\end{tabular}

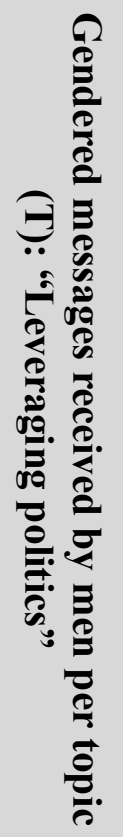



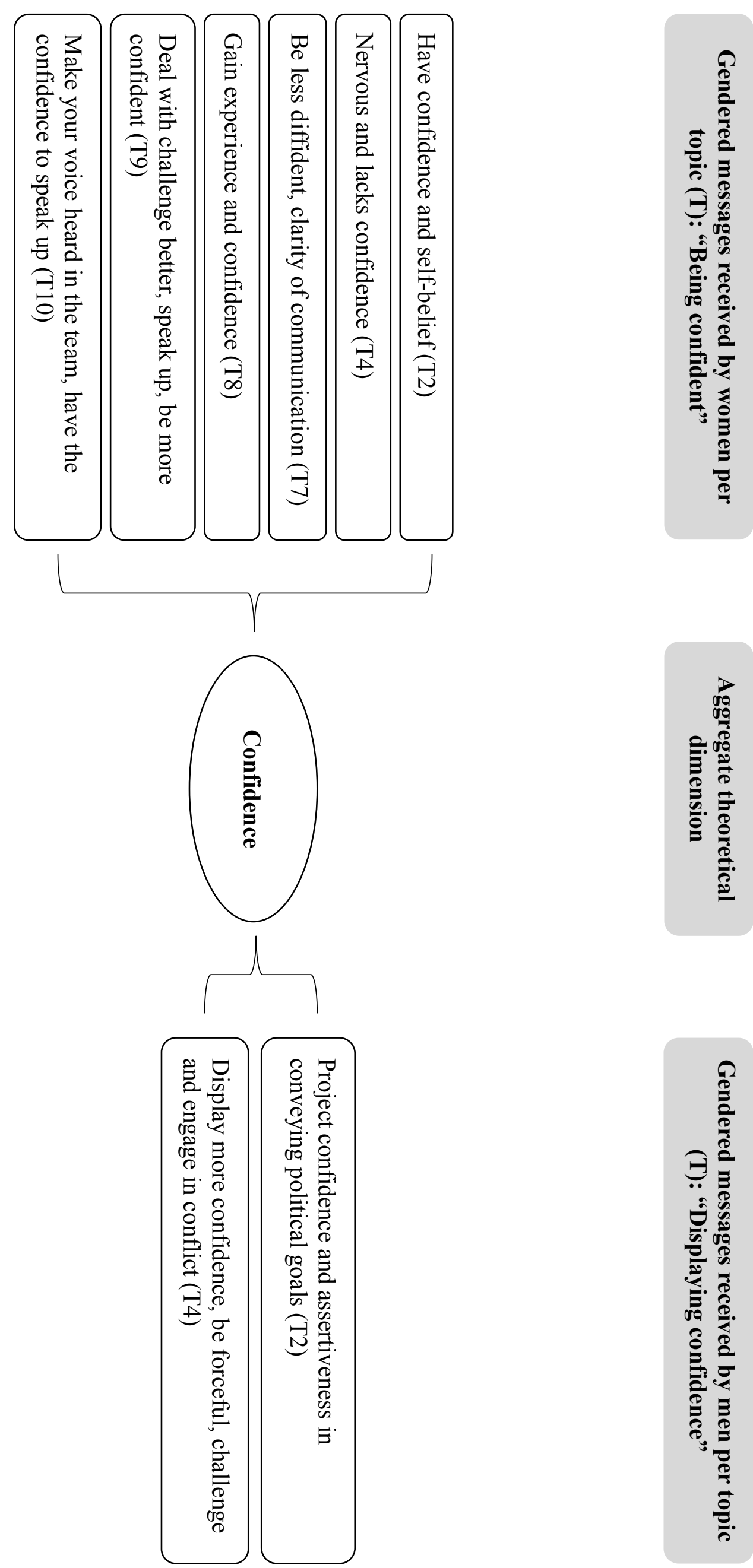


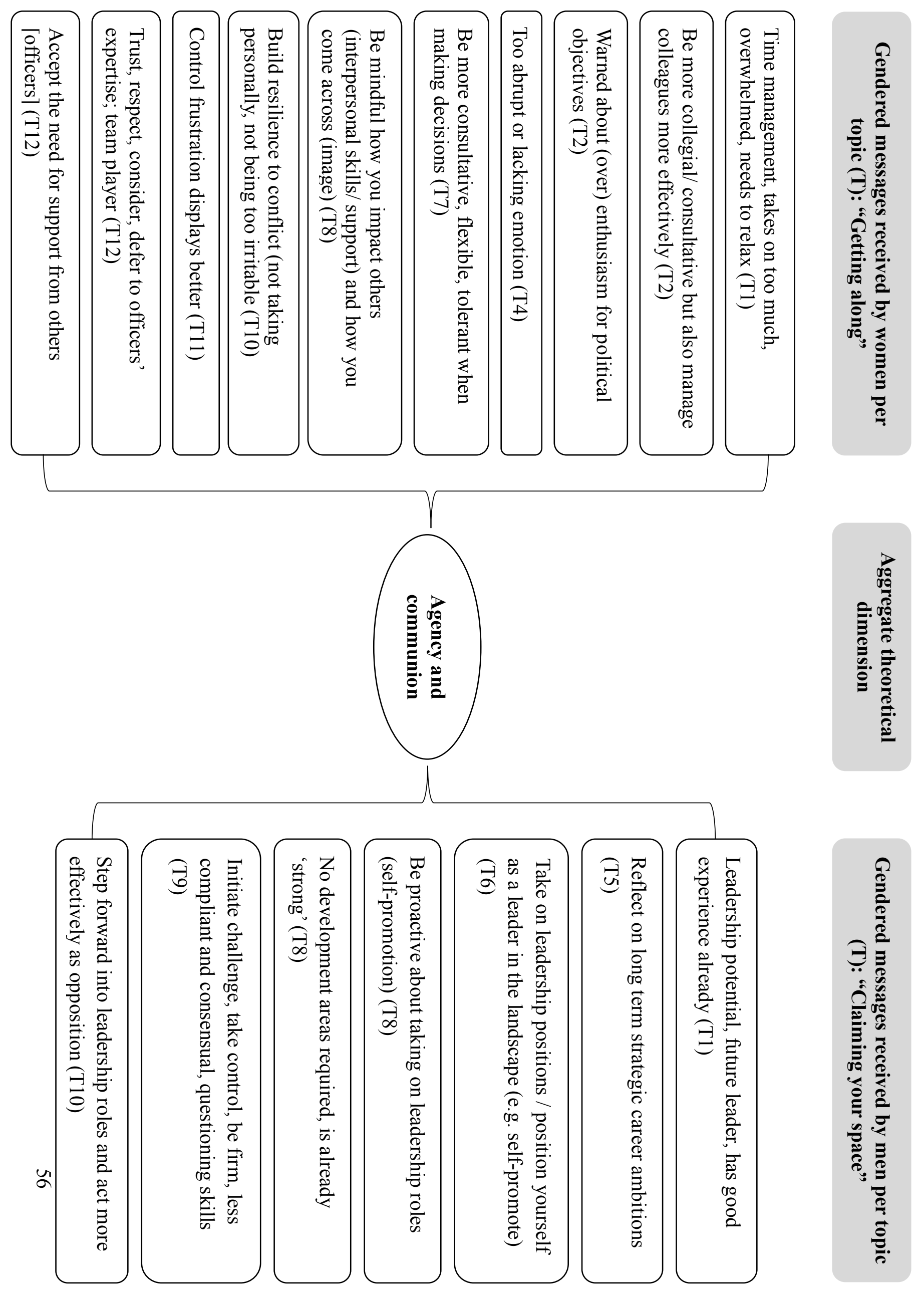




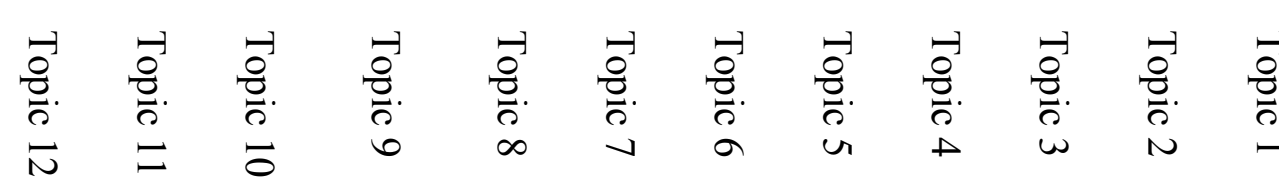

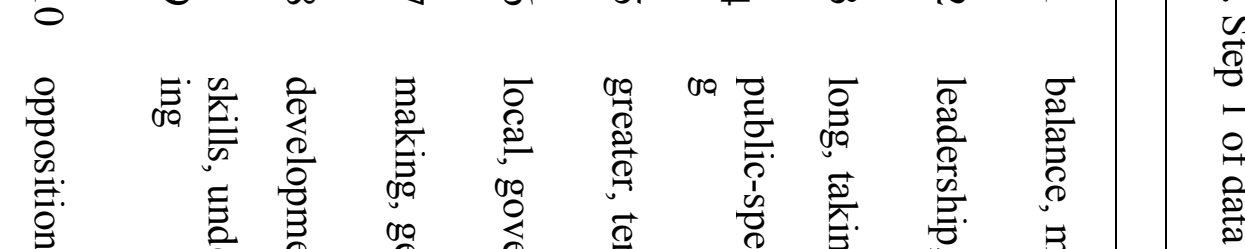

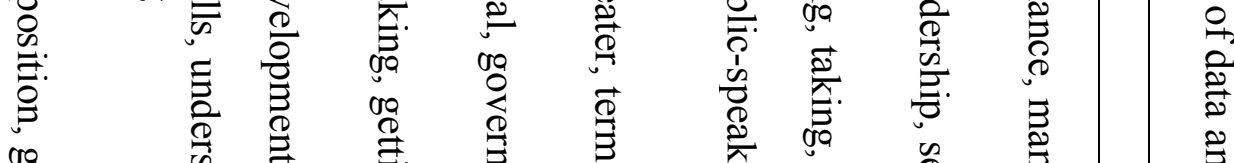

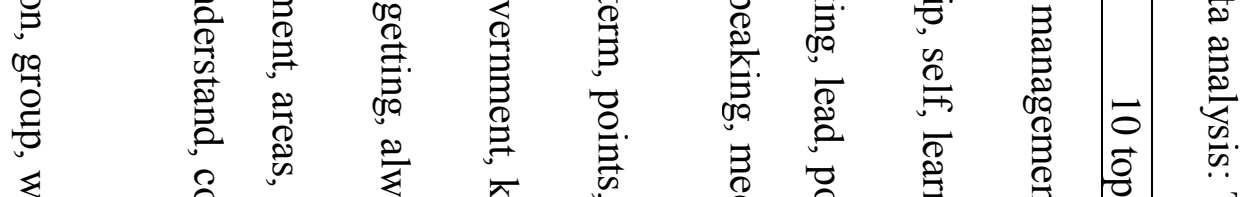

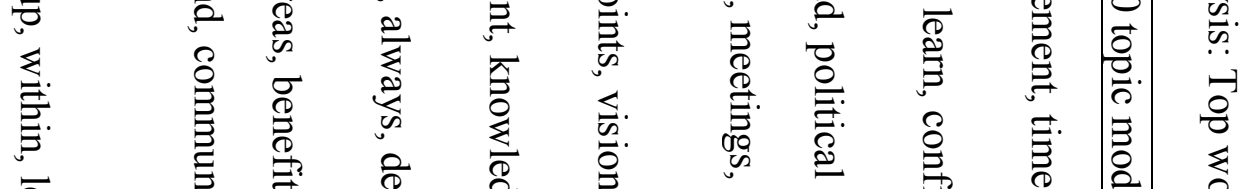

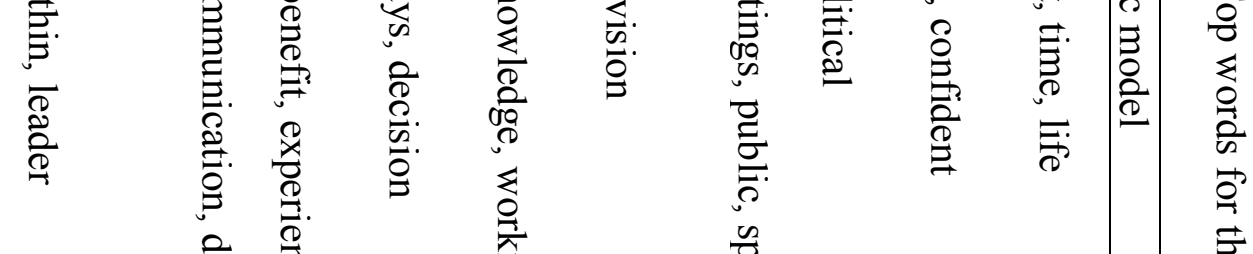

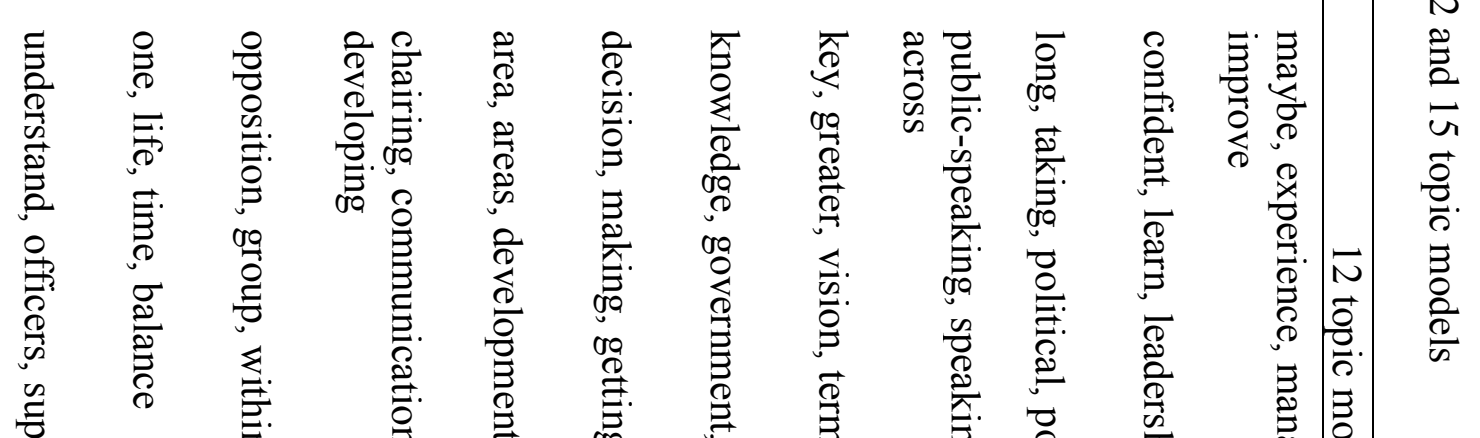

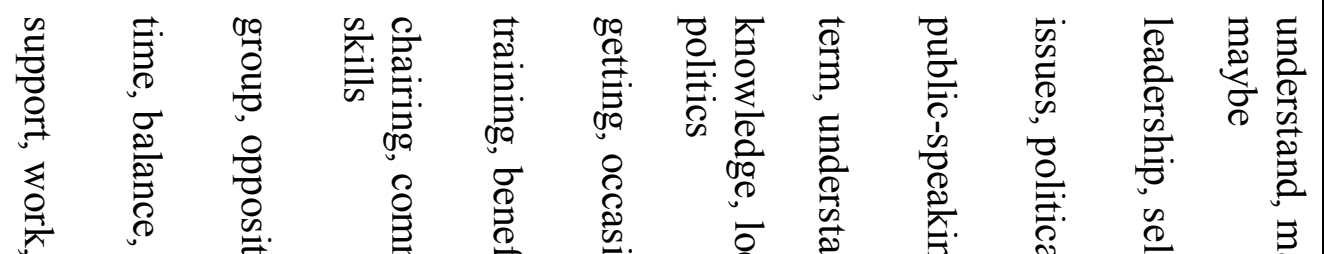

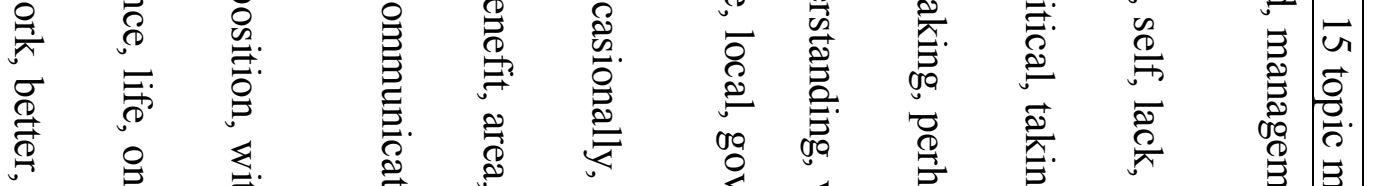

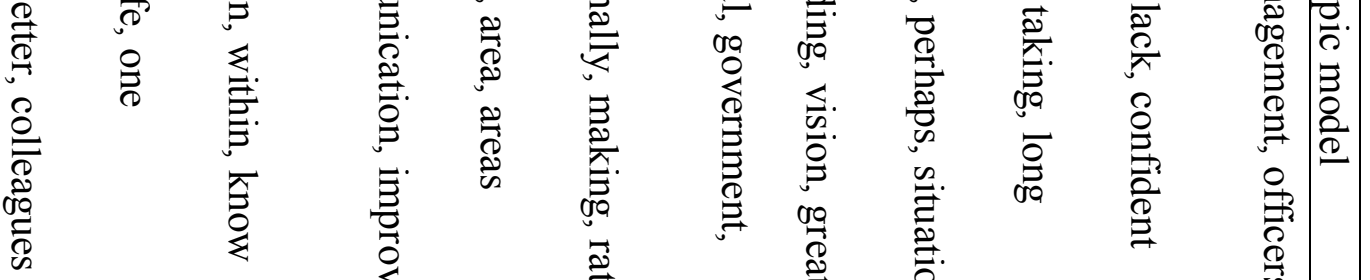

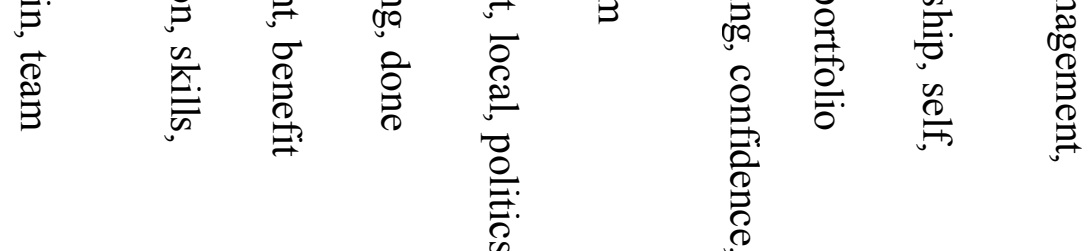
$\frac{\overrightarrow{0}}{\stackrel{0}{0}}$ స 产

홏 言 
$\begin{array}{lll}\overrightarrow{0} & \overrightarrow{0} & \overrightarrow{0} \\ \overrightarrow{0} & \overline{0} & \overrightarrow{0} \\ \vec{\sigma} & \vec{D} & \omega\end{array}$

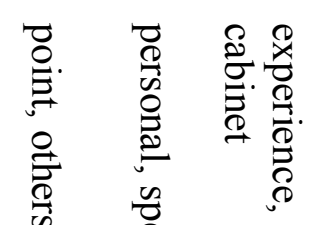

का के

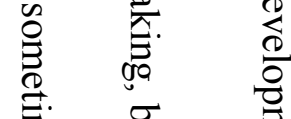

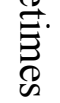

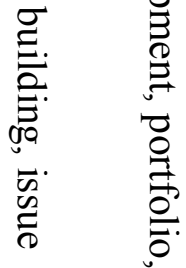

莺 


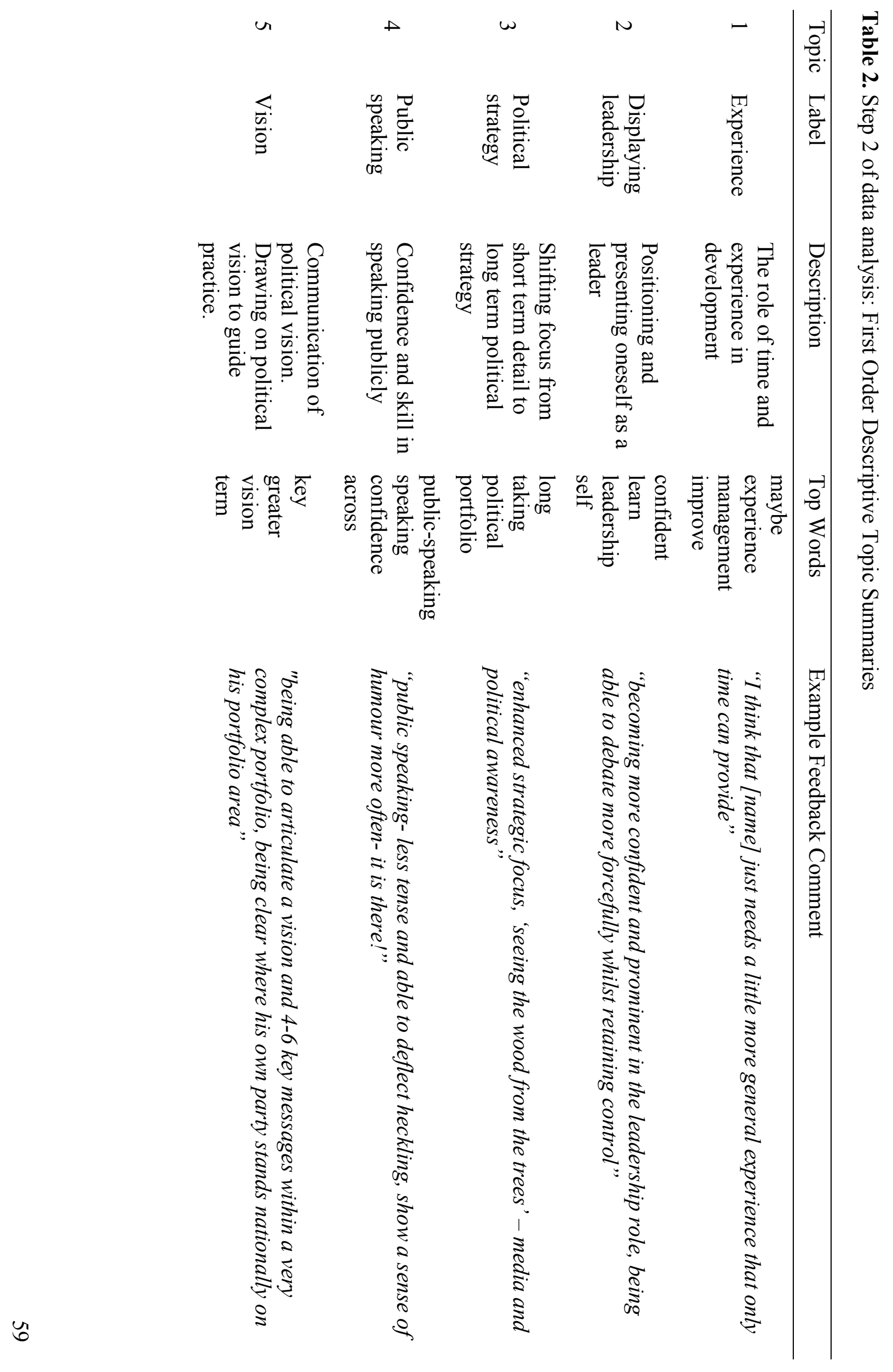




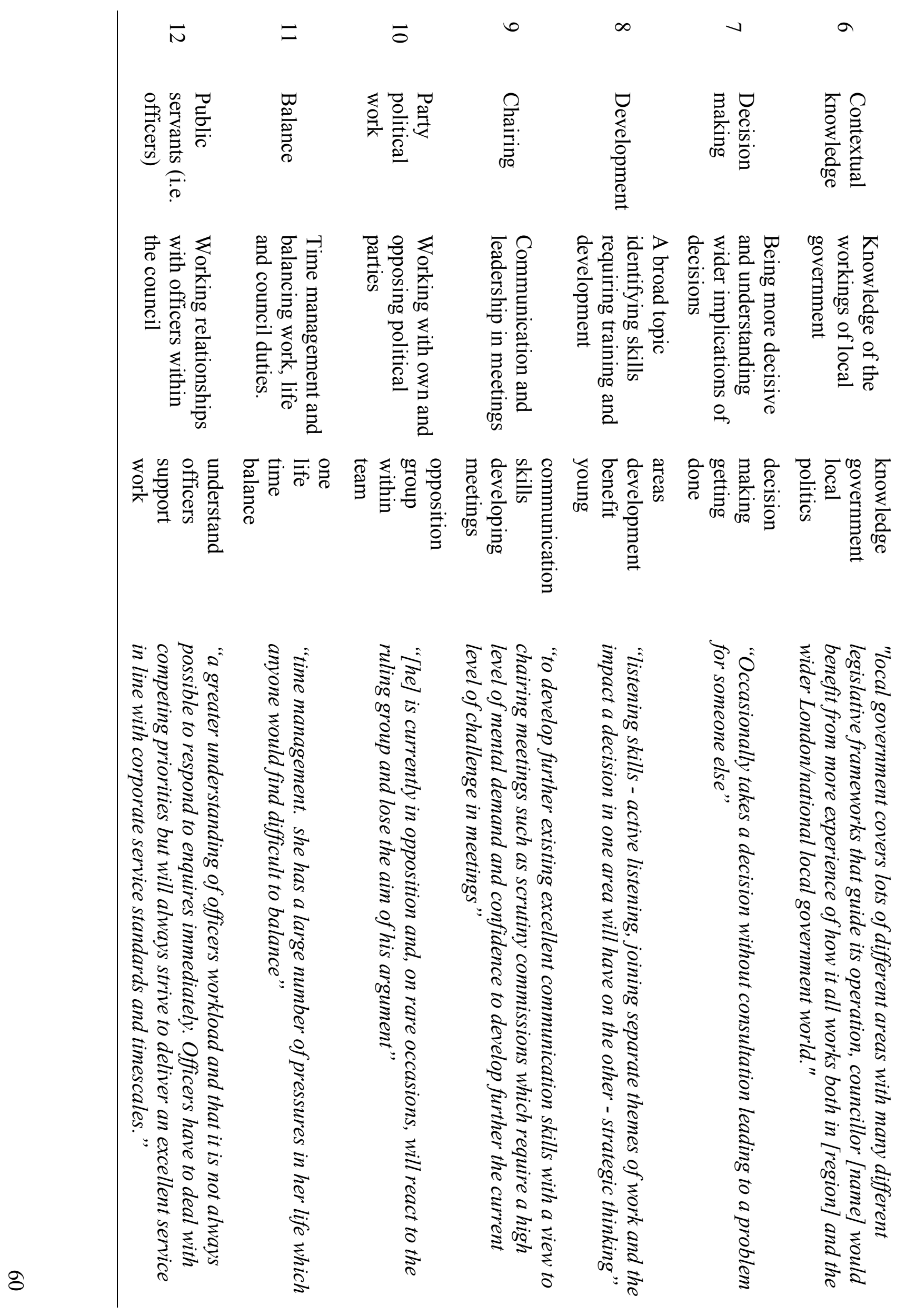




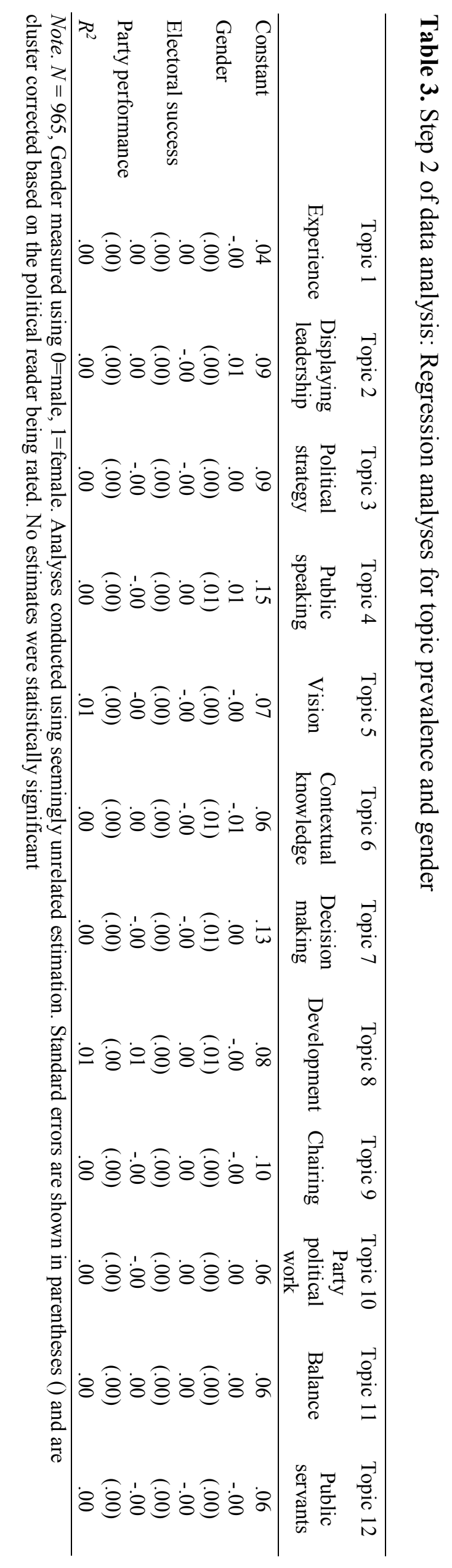




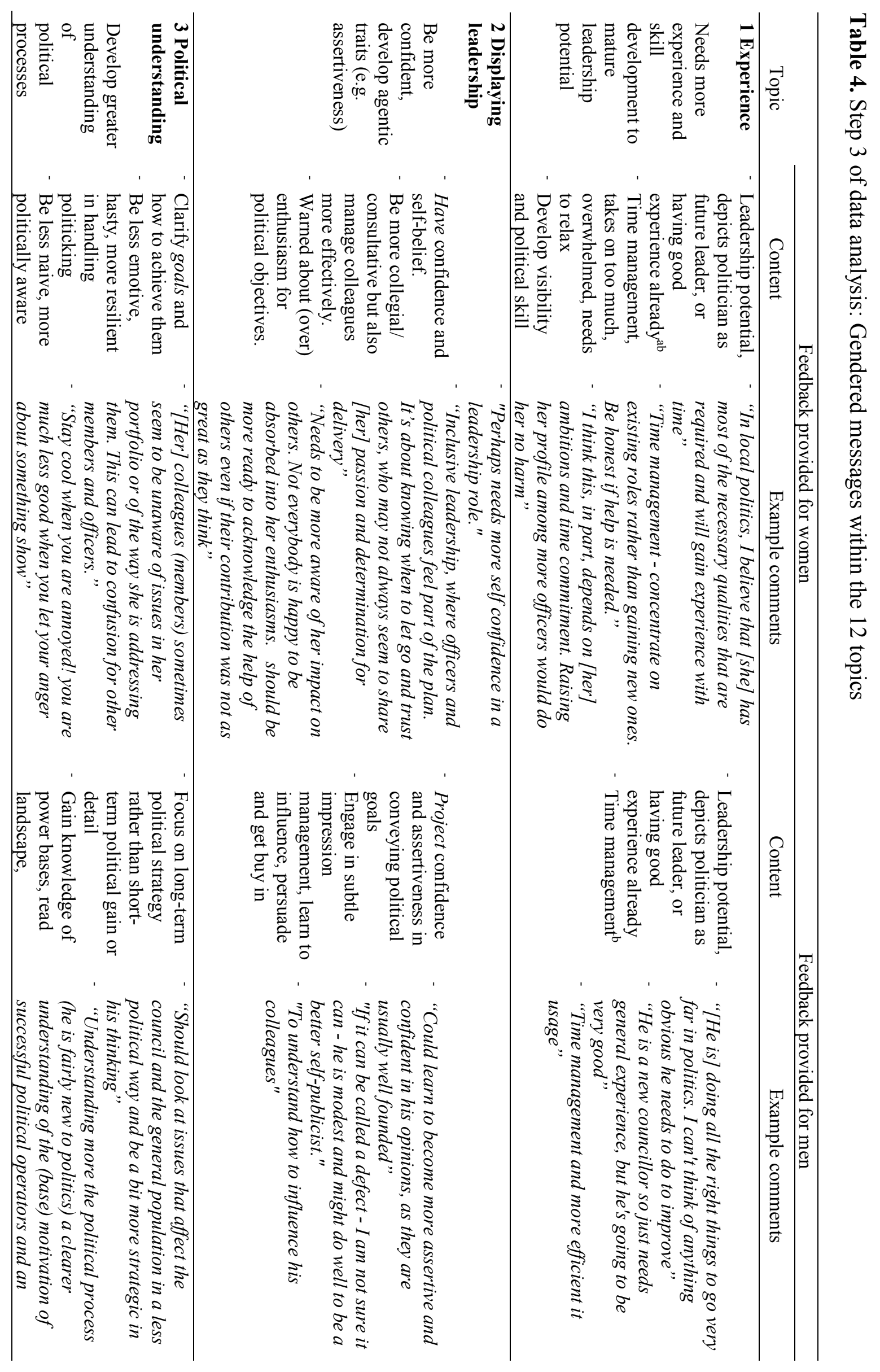




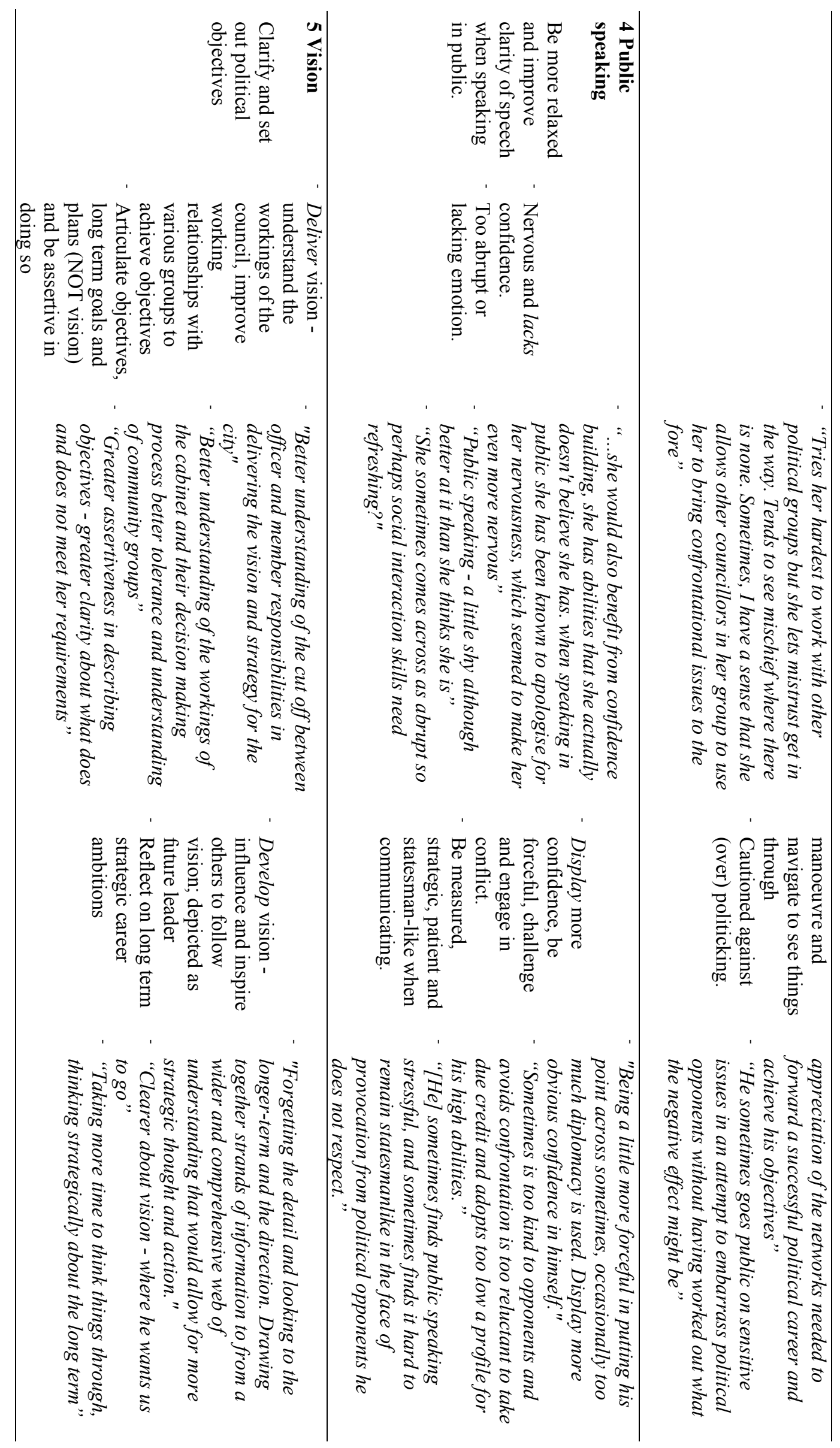




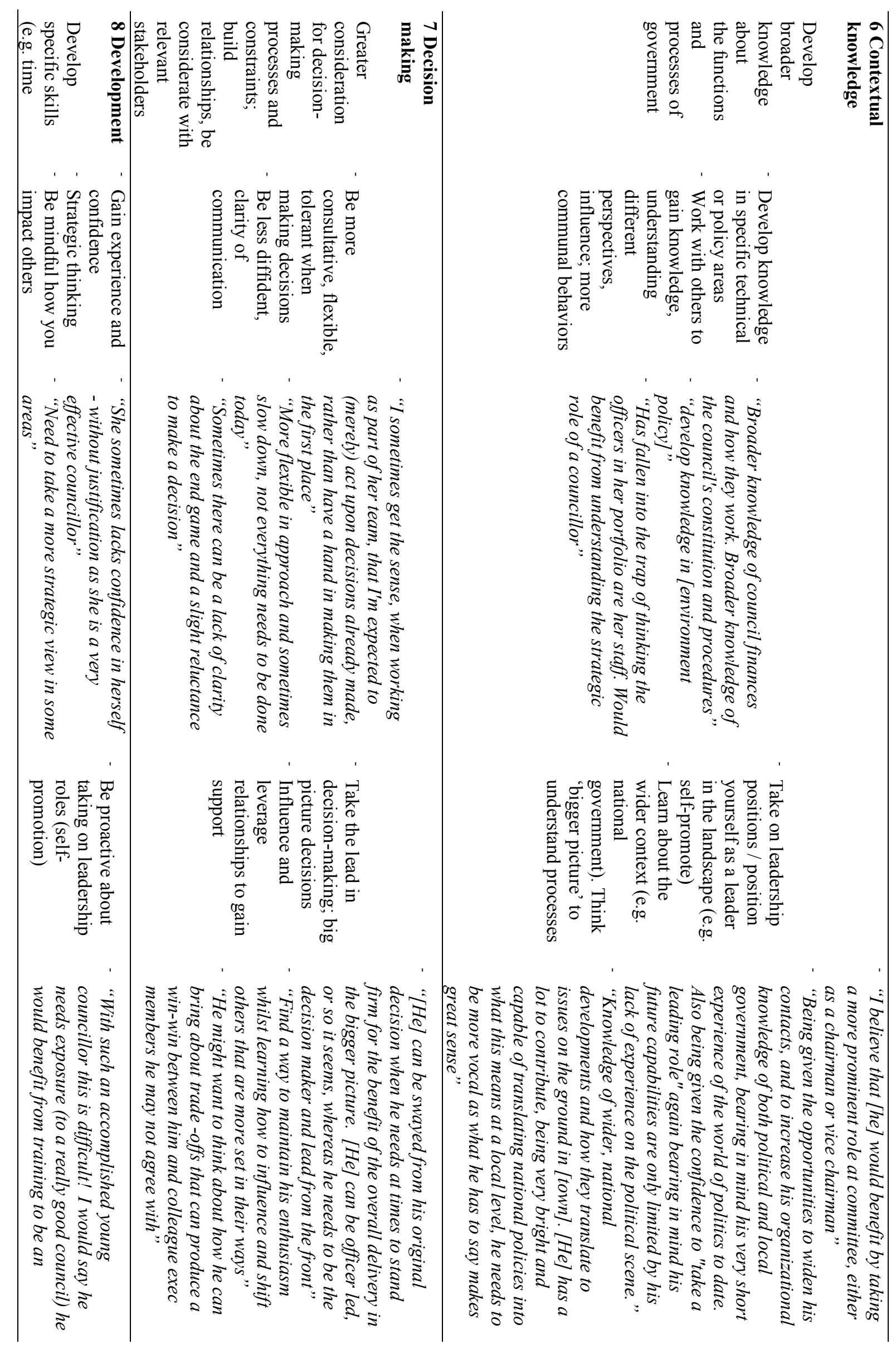




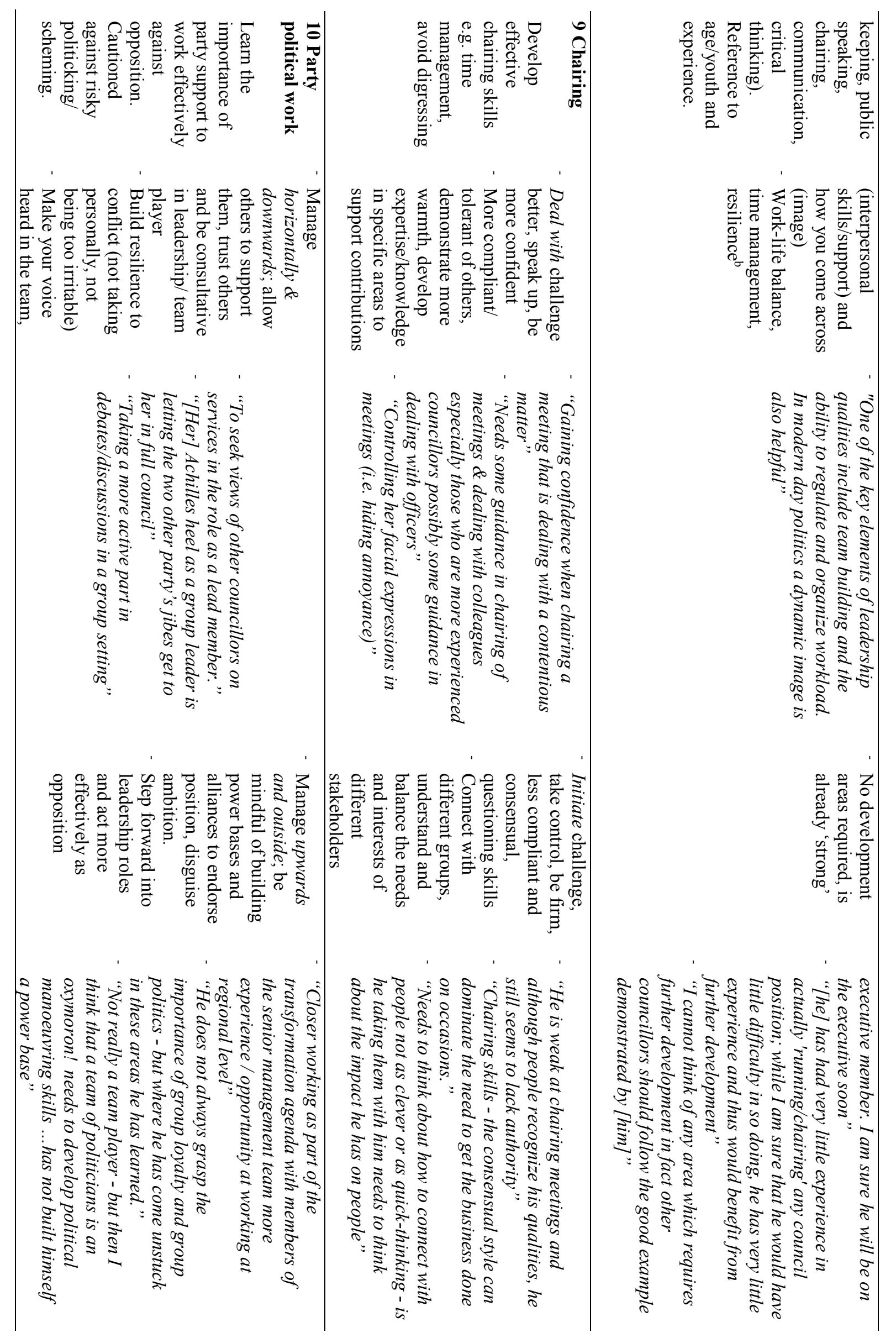



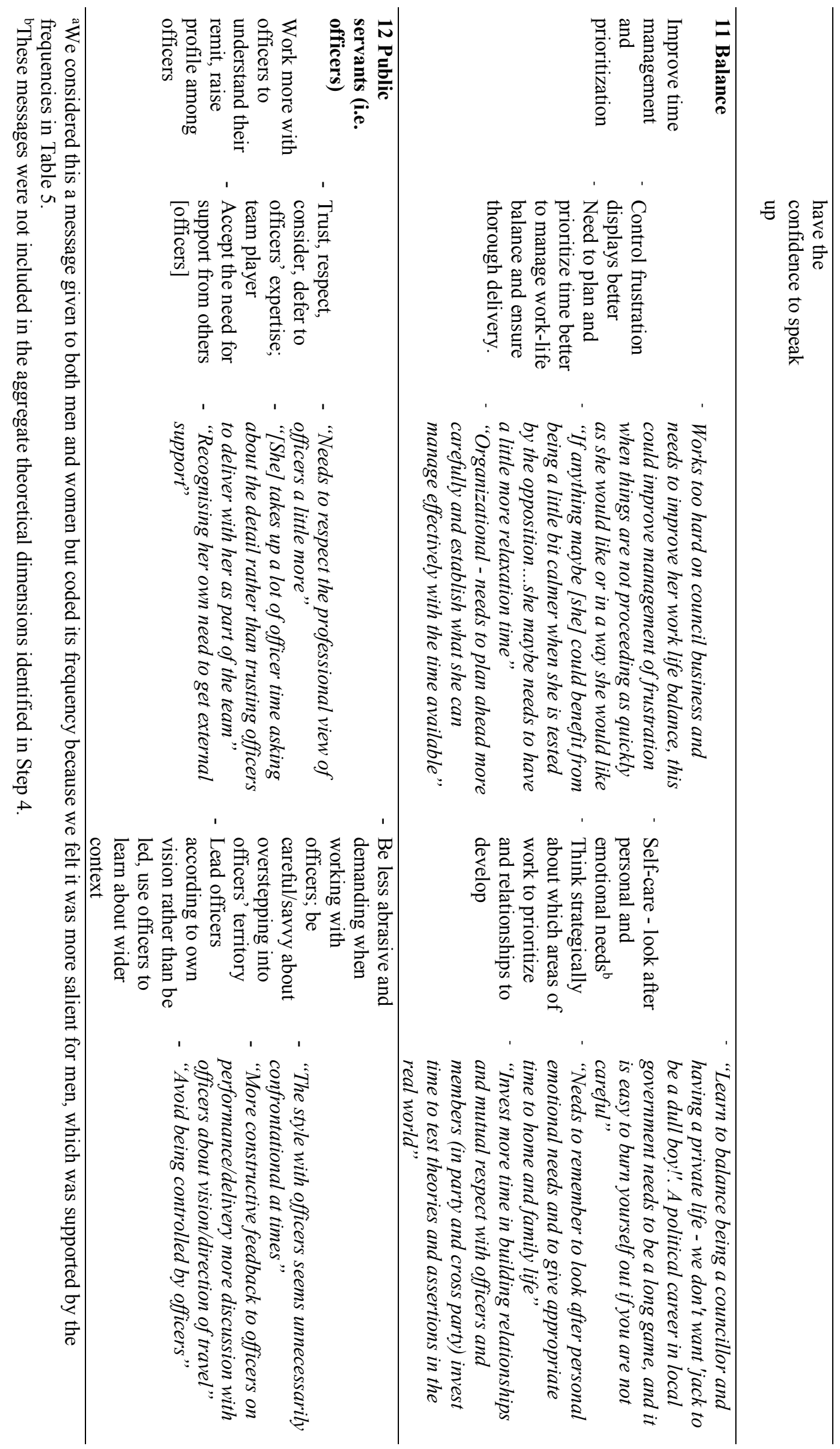


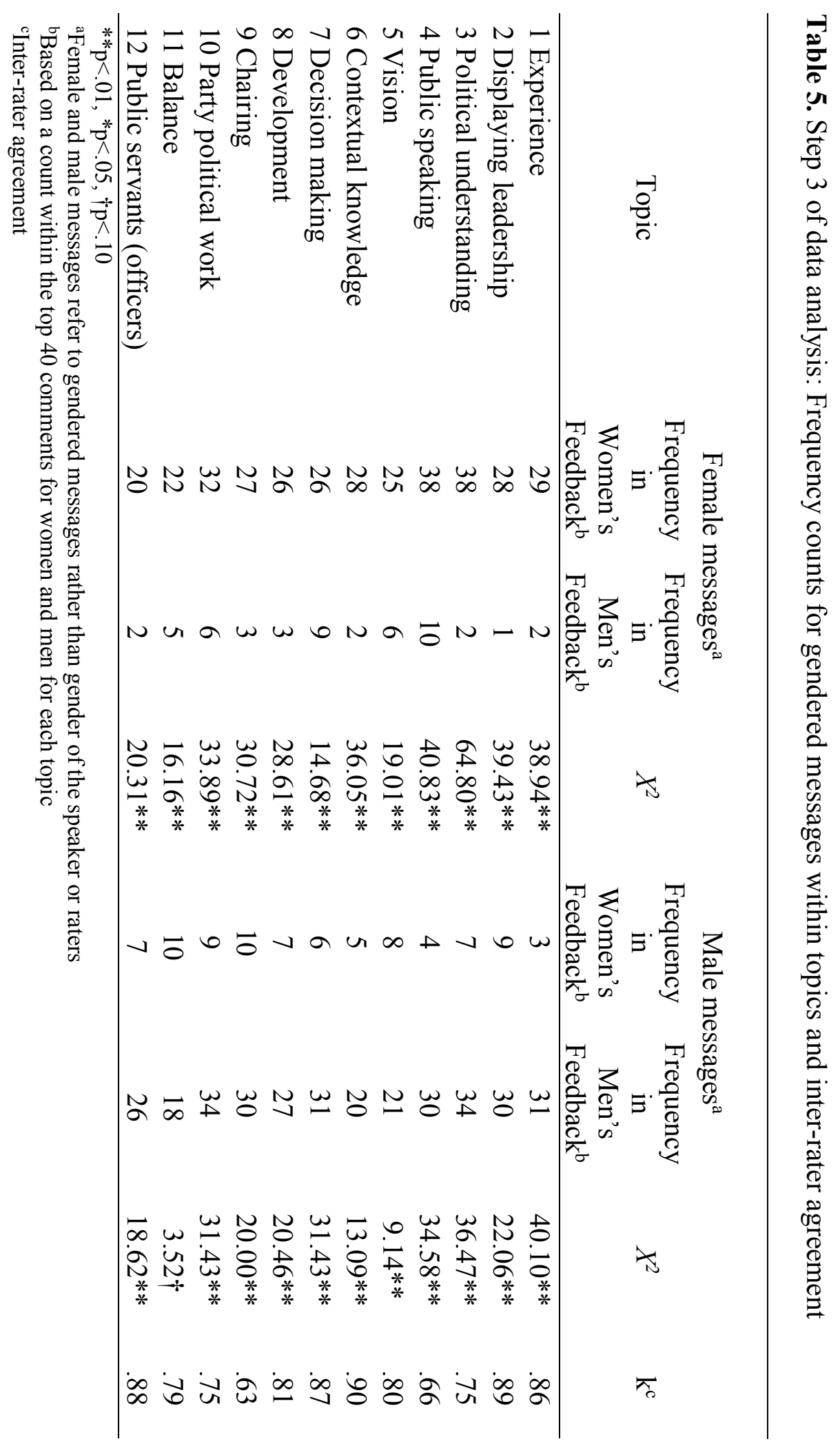


Semantic Coherence

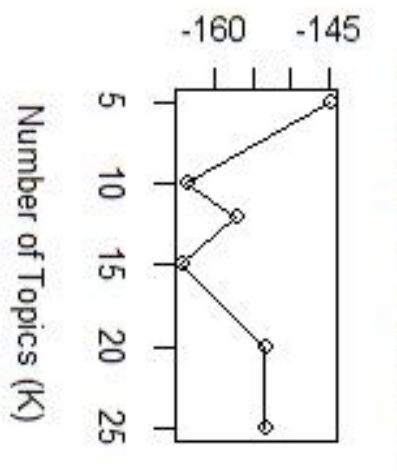

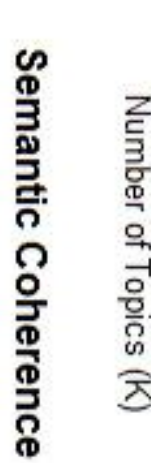

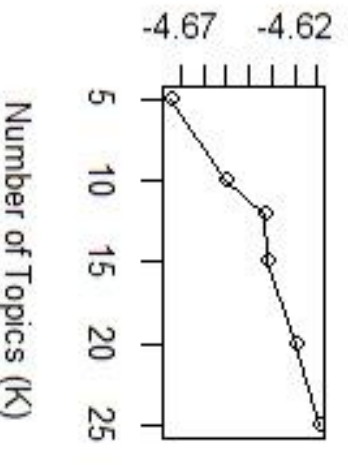

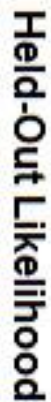

Lower Bound
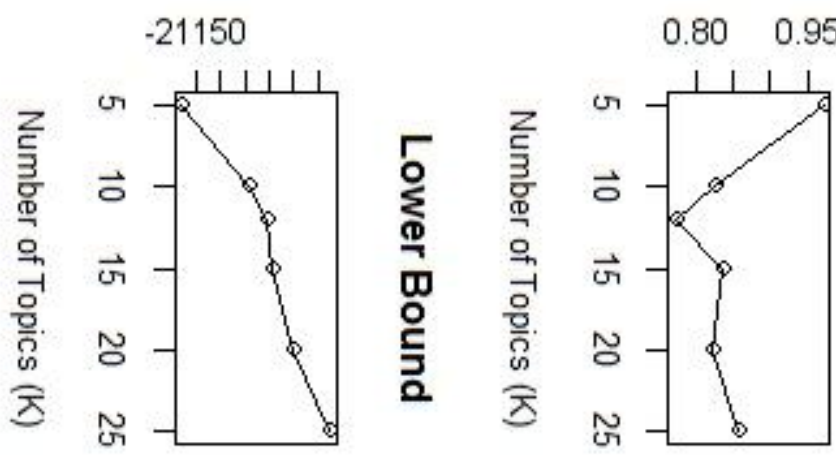

涩 


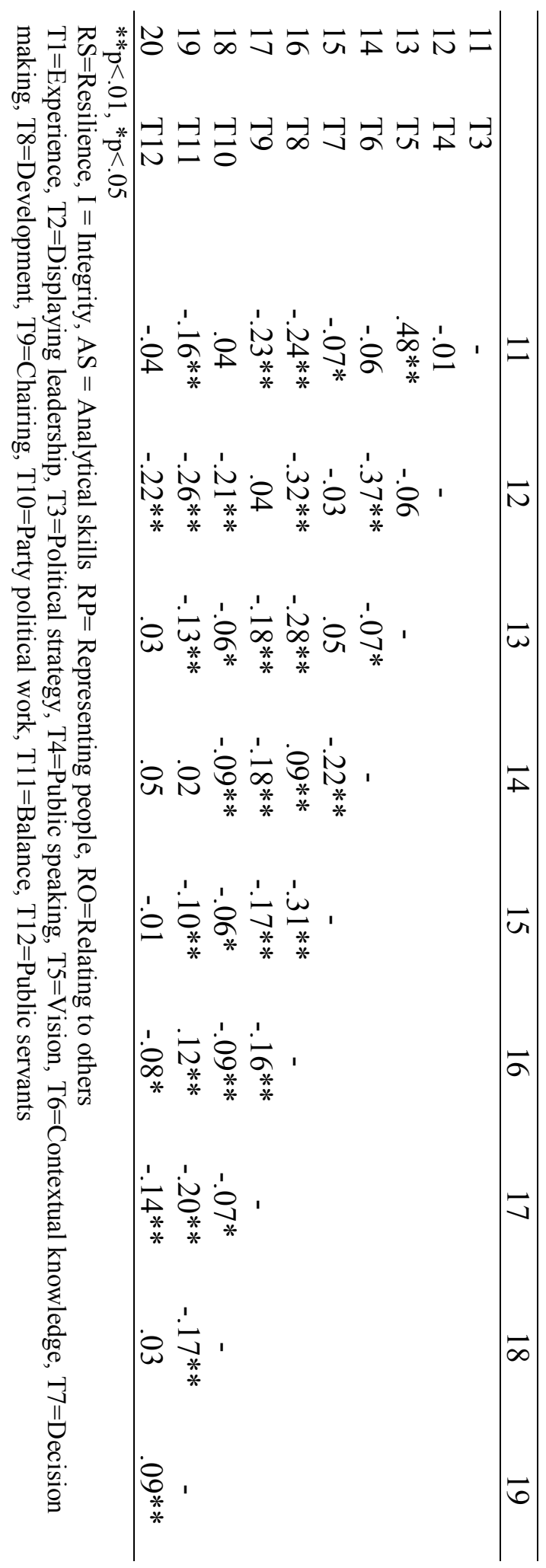

